University of San Diego

Digital USD

1998-03-01

\title{
Toward Cooperative Ethics: A Ricoeurian Reading of the Educational Aim of Jose Maria Arizmendiarrieta Founder of the Mondragon Cooperatives
}

Virgil Lorenzo EdD

University of San Diego

Follow this and additional works at: https://digital.sandiego.edu/dissertations

Part of the Leadership Studies Commons

\section{Digital USD Citation}

Lorenzo, Virgil EdD, "Toward Cooperative Ethics: A Ricoeurian Reading of the Educational Aim of Jose Maria Arizmendiarrieta Founder of the Mondragon Cooperatives" (1998). Dissertations. 643.

https://digital.sandiego.edu/dissertations/643

This Dissertation: Open Access is brought to you for free and open access by the Theses and Dissertations at Digital USD. It has been accepted for inclusion in Dissertations by an authorized administrator of Digital USD. For more information, please contact digital@sandiego.edu. 


\title{
TOWARD COOPERATIVE ETHICS: A RICOEURIAN READING \\ OF THE EDUCATIONAI AIM OF JOSE MARIA ARIZMENDIARRIETA, FOUNDER OF THE MONDRAGON COOPERATIVES
}

\author{
A DISSERTATION SUBMITTED TO \\ THE DISSERTATION COMMITTEE \\ IN CANDIDACY FOR THE DEGREE OF \\ DOCTOR OF EDUCATION \\ SCHOOL OF EDUCATION
}

BY

VIRGIL LORENZO

SAN DIEGO, CALIFORNIA

MARCH, 1998 


\section{ABSTRACT}

Paul Ricoeur and Jose Maria Arizmendiarrieta were contemporaries whose separate works, when brought side by side, provide insights into how community development might proceed at the intersection of the domains of ethics, politics, and economics. In complementary ways they have addressed the reciprocal responsibilities of a society toward its citizens and vice-versa.

In this study I make note of the parallels between Ricoeur's definition of the ethical aim and Arizmendiarrieta's educational aim as this may be gleaned from an anthology of his sayings as well as from statements of those who knew him very well. These similarities provide impetus toward a definition of cooperative ethics. Using the method of interpretation, this definition is amplified at the intersections of the domains of ethics, economics, and politics with the help of regrouped quotes on education from Arizmendiarrieta and following the pattern of Ethics and Politics, an essay of Ricoeur. Referring to the phenomenology of change, I then argue that just as politics is an extension of the ethical aim, socio-economics is the extension of the educational aim.

The methodology involves a rearrangement of quotes and refer to the triple autonomy of texts that Ricoeur has established in his theory of texts. The reconfiguration is 
reminiscent of Ricoeur's mimesis I, II, and III, and lends to the amplification of the definition of cooperative ethics. I call attention to the directive function of education in Arizmendiarrieta's thoughts which complement Ricoeur's reflections on configuration. The example of the University of Mondragon and its cooperatives validates their insights. I cite the implications for community development that the Mondragon experience brings to the world. I suggest that a holistic approach to community development might be best coordinated by a university and that a university can generate a similar network of cooperatives by instituting a "Saiolan type" of enterprise incubator, by coordinating mutual support of member enterprises, and by supporting these efforts with appropriate curricular offering. By way of conclusion, I suggest that cooperators now have another point of departure in their reflections on the ethical commitment of cooperatives and cooperators. 
TO MY WIFE

Reproduced with permission of the copyright owner. Further reproduction prohibited without permission. 


\section{ACKNOWLEDGEMENTS}

A word of thanks to Jone Arroitajauregi who graciously provided me updates on Saiolan's activities, to David Hererra who helped me translate the Pensamientos, and to the members of my committee for their insightful suggestions. 
TABLE OF CONTENTS

\begin{abstract}
LIST OF ABBREVIATIONS . . . . . . . . . . . . . . . . . . . . V
LIST OF APPENDICES . . . . . . . . . . . . . . . . . . . vi CHAPTER

1. STATEMENT OF THE ISSUE . . . . . . . . . . . . . . . 1

Background of the study . . . . . . . . . . . . 2

Two great thinkers . . . . . . . . . . . . 2

The Pensamientos... . . . . . . . . 3

Resonance in Ricoeur . . . . . . . . . . . . 4

Education as core... . . . . . . . . . . . 6

Two Christian contemporaries . . . . . . . . 8

Importance of the study . . . . . . . . . . . . . 9

Education and community building . . . . . . . 9

The continuing search for cooperation . . . . 10

The Mondragon experience . . . . . . . . . . . 11

Delimitations of the study . . . . . . . . . . . 12

Specific Terminology . . . . . . . . . . . . . 13

2. REVIEW OF IITERATURE . . . . . . . . . . . . . . . . . . 19

Introduction . . . . . . . . . . . . . . . . . 19

Arizmendiarrieta on the Educational Aim . . . . . .21

Being learned and being a person . . . . . . . . 22

Being learned and being free. . . . . . . . . . 23
\end{abstract}


Education and cooperation........ 25

Arizmendiarrieta and Economic Justice for All. . . 25

Christian vision of economic life . . . . . 26

Christian life and justice . . . . . . . . 29

Arizmendiarrieta, Paolo Feire, and Liberation. . . 30

Ricoeur on the Ethical Aim. . . . . . . . . . 34

Narrative identity and the other . . . . . .36

Aiming at the good life... . . . . . . 39

With and for others: solicitude...... . . 41

In just institutions......... . . . 45

Ricoeur on the ways of Knowing . . . . . . . . 4 48

Explanation and understanding . . . . . . . 49

Theory of text............ . . . . 50

Theory of action. . . . . . . . . . . . 51

Theory of history . . . . . . . . . . 54

3. INTERPRETATION AS METHOD . . . . . . . . . . . 57

The Philosophical Tradition of Ricoeur . . . . . . 57

Linking explanation and understanding . . . . 58

Interpretation as method . . . . . . . . . . .59

Ricoeur Using Interpretation As Method . . . . . . 60

Narrative theory and personal identity as

dialectics between selfhood and sameness. 61

Character and the plot.......... 62

The self and the ethical aim....... 64

Using Ricoeur's Philosophical Tradition . . . . . 64 
Using the triple autonomy of text as basis. . 64 Interpreting the texts........... . . . . . . 66 Background of the Researcher . . . . . . . . . 67

My short story . . . . . . . . . . . . . 67

My interest in the compelling story of Mondragon. . . . . . . . . . . . 69

4. THE ETHICAL AIM FOR COOPERATORS . . . . . . . . . . . 73 Definition of the Ethical Aim for Cooperators . . . .73 Cooperative Ethics, Education, and the Domains of

Economics and Politics . . . . . . . . 80

Interpretation at the intersection of domains . 80 Arrizmendiarrieta's words on these domains. . . 82 The mediating role of education . . . . 82 Responsibility for one's education. . . .84 Equal opportunity and the timeliness of education... . . . . . . . . 85 Continuous and continuing education . . 85 Education, ethics, and socio-economics . .86 Education, politics, and socio-economics. .87 Education, ethics and politics . . . . . . . 87 Interpretation at the intersection of ethics and socio-economics . . . . . . .88 Interpretation at the intersection of politics socio-economics . . . . . . . . . . 89 Interpretation at the intersection of 
ethics and politics . . . . . . . . . 91 Working in solidarity as an aspect of the good life... . . . . . . . . . . . . . . . .

A teleology proper to cooperatives . . . . . . .95 The Example of the University of Mondragon

and Its Cooperatives . . . . . . . . . . . . . . . . . . Political realism . . . . . . . . . . . . 99 Economic realism . . . . . . . . . . . 100 Educational realism:

teaching the cooperative way of life. . 101 Implications for Community Development . . . . . 104 Recommendations: Toward a Cooperative Catholic

University . . . . . . . . . . . . . . . . . . . . . . . .

Democratic structure. . . . . . . . . 105

Ethical orientation . . . . . . . . . . . . . . . 05

Entrepreneurial orientation . . . . . . . . . . 106

Christian community orientation . . . . . . . . . . .

Coordination with Catholic secondary schools . 108

5. CONCLUSIONS . . . . . . . . . . . . . . . . . . 109

APPENDIX . . . . . . . . . . . . . . . . . . . 114

REFERENCES . . . . . . . . . . . . . . . . . . . . . . . . . . . . . . . 


\section{LIST OF ABBREVIATIONS}

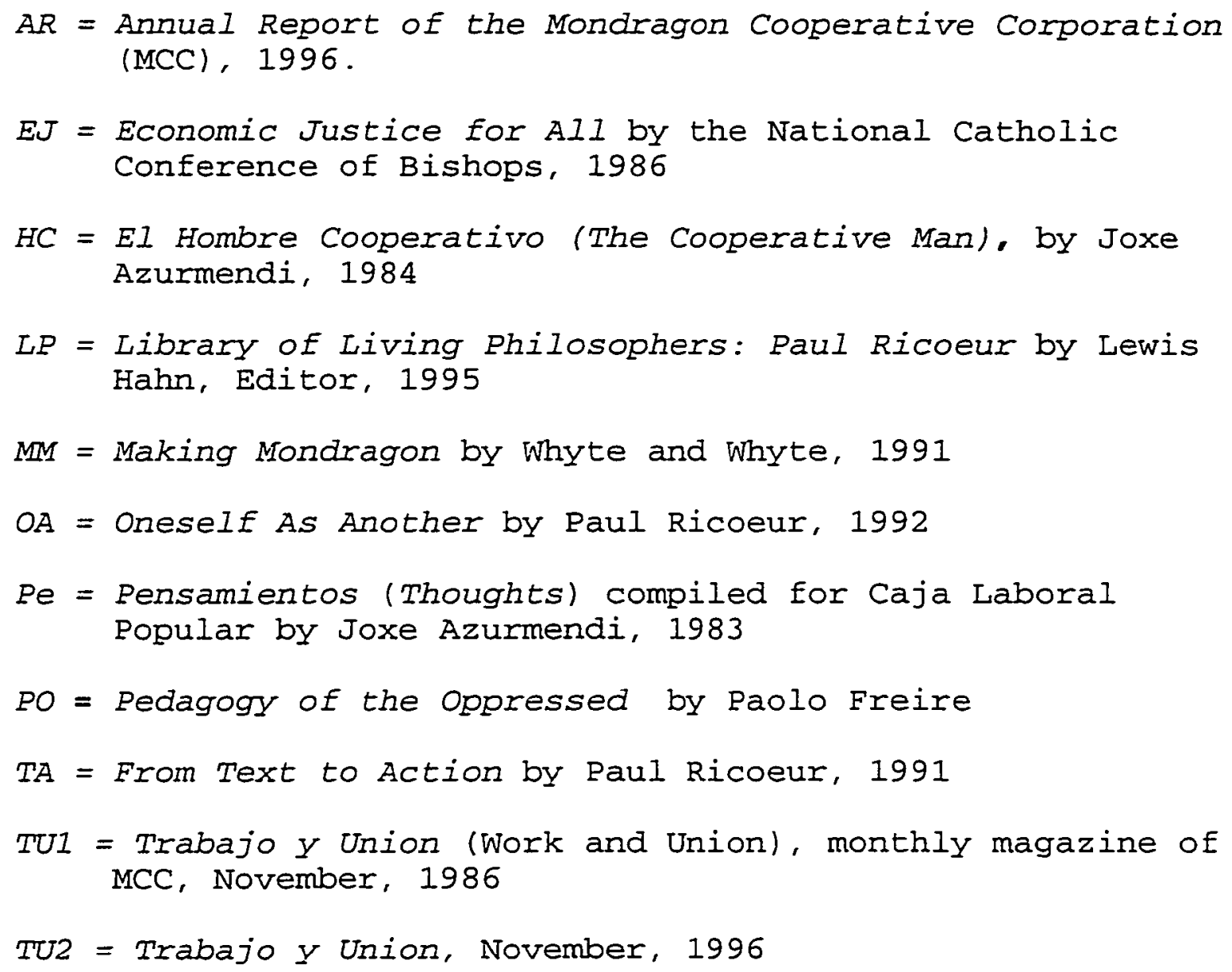




\section{LIST OF APPENDICES}

APPENDIX A: INTERSECTION OF DOMAINS . . . . . . . . . . 114

APPENDIX B: PRINCIPLES OF THE INTERNATIONAL

COOPERATIVE ALLIANCE . . . . . . . . . . 115

APPENDIX C: COOPERATIVES 100 . . . . . . . . . . . 118

APPENDIX D: FORTUNE 100................ . . 127

APPENDIX E: PART I, CHAPTER 5 OF THE PENSAMTENTOS. . . 130 


\section{CHAPTER 1}

\section{STATEMENT OF THE ISSUE}

Understanding the principles of social and economic justice as lived by the members of the Mondragon Cooperative Corporation (MCC) can be achieved via the thoughts of Fr. Jose Maria Arizmendiarrieta. A fuller philosophical explication of the justice context of MCC can be achieved via the thoughts of the philosopher and theologian, Paul Ricoeur. Indeed, explicating some of the influences of their common mentor, Emmanuel Mounier, can shed light in the origins of their respective commitments to life in a just society.

Gleaning from the Pensamientos, an anthology of his thoughts, as well as from statements of those who knew him well on the matter, the educational aim of Arizmendiarrieta may be stated as the engagement of people through education in settings where they can work in solidarity to usher in a humane and just social order. Ricoeur on his part defines the ethical aim as the desire to live the good life, with and for others, in just institutions. My thesis is that a Ricoeurian reading of the Pensamientos will reveal parallels and complementarity between the ethical aim of Ricoeur and 
the educational aim of Arizmendiarrieta that help define what I call cooperative ethics. I shall amplify this definition by placing excerpts on education from the Pensamientos at the intersection of the domains of politics, socio-economics and ethics, and by elaborating on the "world of the text" that emerges from these quotes. I will argue that just as Ricoeur's ethical aim is extended by politics, so does socio-economics extend Arizmendiarrieta's educational aim and that therefore work and all economic activity is never ethically neutral.

\section{Background of the study}

Two great thinkers. As an attempt to look far into the possibilities of human collaboration, this study is made possible thanks to the horizons these two men have opened and which I will attempt to fuse. Ricoeur is the author of 20 books and over 500 articles, was a member of seven learned societies, and a recipient of honorary degrees from 30 universities worldwide (LP, 609). Arizmendiarrieta also wrote extensively but his greatest accomplishment is his being acknowledged as the founder of the Mondragon Cooperative Corporation (MCC) which issued from a technical high school, now the University of Mondragon. The example in human collaboration that MCC holds before the world is a realization of Arizmendiarrieta's thoughts. Together, these 
two men provide important considerations for the conceptualization of cooperative ethics the proper domain of which includes cooperative work and living. From these considerations one can draw ethical guidelines for a university-driven community development that involves parish communities and their schools.

The Pensamientos. The prestige of MCC has led to the demand from groups that promote social justice and cooperative work arrangements as well as from universities for study tours to Mondragon. Their websites are linked to the webpage of MCC and give a schedule of their tours. Consequently, a similar interest in the Pensamientos now exists outside MCC. Within MCC, this interest is a constant. On the tenth and twentieth death anniversaries of Arizmendiarrieta (1986 and 1996), the November issues of Trabajo y Union (Labor and Union), dedicated their pages to recalling the legacy that Arizmendiarrieta left behind. Among those recalled are his Pensamientos, a pocketbook anthology of key statements found in the works of Arizmendiarrieta and compiled by Joxe Azurmendi with the intent of providing food for thought to the now 30,000 member-workers of this network of 115 cooperatives (AR, 52) as they ponder the future of their enterprises. The 1996 November issue makes good use of this anthology on its back 
cover with an imagined consultation with Arizmendiarrieta whose responses are all taken from the book. One question leads Arizmendiarrieta to say, "Education is the economy since without education goods and services that are difficult to obtain cannot be produced nor distributed. The only endowment and valuable good that does not tend to lose its worth is that of skills acquired, that of training and formation." Arizmendiarrieta refers often to the tie between education and the economy in the Pensamientos and these two in the context of power, democracy, and participation of citizens in decision-making. He writes, "Knowledge is power and in order to democratize power, one must socialize knowledge beforehand. We accomplish nothing with the proclamation of rights, if afterwards the citizens whose rights we have proclaimed are incapable of administering those rights if, to be able to act, these citizens have no recourse but to count on a few indispensable people (Pe, 193)." Another quote refers to the notions of equality and freedom: "People who are conscious of their dignity, or who would not want to be at the mercy of someone foreign and from the outside must promote before anything else the cultivation and development of their own intelligence and will (Pe, 202)."

Resonance in Ricoeur. These thoughts find parallels in 
an essay by Paul Ricoeur where he confronts politics, socioeconomics, and ethics. In Ethics and Politics (TA, 326), Ricoeur uses three circles to illustrate the intersection of ethics, politics, and socio-economics (see Appendix A, 1). He notes carefully that the circles intersect, not subordinate each other. Each has its own center of interest but there are areas of overlap which he calls "zones of confrontation."

Ricoeur defines politics as the role of the state in the community and in turn defines the state broadly as the organization of the historical community which enables the community to make decisions and to act in concert. Whatever Ricoeur says in this essay about the State I apply to the cooperative, mutatis mutandis, especially that part where he claims the state is the instrument of the community for its survival, the guarantor of equality for all before the law, and the educator of all in the use of freedom through discussion (TA, 331). Considering how many people become sick, even commit suicide, due to unsafe or unjust working conditions and considering how many families break up and "die" as a result of unemployment, the cooperative, like the State, is an instrument for survival and, by its constitution and bylaws, the guarantor of equality for all its members as the state does for its citizens. 
The similarity between the state and the cooperative is even more striking when one notes that Ricoeur relegates to the state the role of educator in a similar manner that Arizmendiarrieta considers the cooperative as an educational enterprise. Education is an important part of the function of the State whose task, according to Ricoeur, is to reconcile two rationalities, namely, the technico-economic form and the reasonable that is found in the customs and mores of the community. In other words, the state is "the synthesis of the rational and the historical, of the efficient and the just (TA, 331)." This synthesis is evolved and critiqued in public by politicians and the media as well as in the classrooms and places of work by the educators of the community. Using the diagram by Ricoeur, the zone where all three circles intersect may be designated to symbolize the area of synthesis (see Appendix A, 2).

Education as core. In order to appreciate the educational aim of Arizmendiarrieta in its broadest sense, I propose to situate the educational enterprise that he began in Mondragon, even as early as 1943, in this area of synthesis and posit that education as a conduit of change has a directive function in the three domains. A friend and biographer, Jesus Larrañaga, describes Arizmendiarrieta's theory of education as that of engaging young people-even when very young-to accustom themselves to taking practical 
actions. "[T]hey had to participate in initiatives of any kind, from making things for Christmas to taking steps in any other activity. The important thing is that there be continual practice, so that initiative, responsibility, and commitment can be demonstrated (MM, 242)." Javier Retegui, President of the Polytechnic School and Director of the Entrepreneurial Division, in an interview with Jesus Ginto in 1986 said, "Education, understood as the basic principle of the emancipation of workers and of society was a constant in the life and thoughts of Fr. Jose Maria. ... He used to repeat often that the important thing was a community engaged in a rich variety of activities and not rich individuals in a poor society (TU1, 47)."

Arizmendiarrieta aimed at no less than the creation of a new world when he wrote "Education is the natural and indispensable point of support for the promotion of a new social order that is humane and just"(Pe, 191). This resonates very well with the "Just institutions" in the third component of Ricoeur's definition of the ethical aim (OA, 169). It is the necessary environment of living the good life with and for others, the other two components of Ricoeur's definition.

Informed by the works of the Pioneers of Rochdale, the educational aim of Arizmendiarrieta includes the language of the principles enunciated at the centennial of the 
International Cooperative Alliance in 1995 (see Appendix B) but also goes farther. In order to sustain the vision of a new society that the cooperatives, as an educational movement ( $P e, 218$ ), are to bring about, he sought a change of heart, a new mentality (Pe, 192), one that could enable a cooperator to opt "To act, not to win; to create, not to possess; to render productive, not to dominate (Pe, 147)." A few years before his death, he noted with satisfaction, that his former students pursued further studies in order to translate these to work, and they worked not only to gain their daily bread but also to pursue new forms of society (HC, 818). At first reading, however, this latter expression of the educational aim of Arizmendiarrieta either seems to contradict the sense of ownership that is expected of cooperators, or is too lofty for any individual to aim for. At this juncture, the philosophical considerations of Ricoeur on the ethical intention can help to bridge the apparent gap between ownership and detachment, and is presented in Chapter 2 .

Two Christian contemporaries. Although his philosophy has rigorously maintained and observed its independence from any theology, Ricoeur was a French Protestant who professed his biblical Eaith in his intellectual autobiography published in 1995, a year before he died at the age of 84 (LP, 53). Arizmendiarrieta, on his part, was assistant 
pastor of the Catholic parish of Mondragon, Spain, from 1941 until his death in 1976 at the age of 61 (TU1, 23). True to the meaning of the word "catholic," the institutions he inspired are all-inclusive, open to the "universal man," a phrase referring to the description that Ricoeur used for those engaged in the technico-economic domain of the human community (TA, 327). That "universalization" of the enterprise has led MCC to be "apolitical and aconfessional," a phrase used in a conversation in October, 1997, with an MCC director at Otalora, MCC's center for advanced training in cooperative management. Ironically, "a-everything," said a pastor in one of Mondragon's churches, jestingly adding the phrase, as if to underscore the distance that MCC has gone from the community that originally begot it: the Catholic parish of Mondragon. This distance is a fulfillment of what Arizmendiarrieta quoted and lived: "To create, not to possess; to render productive, not to dominate."

\section{Importance of the study}

Education as community building. The philosophy of Ricoeur and the legacy of Arizmendiarrieta are two contemporary currents that provide new perspectives from which to rethink the relationship between education, cooperative work, and community building. Cooperative work is community building and is a conduit of change. Work that 
is undertaken in the spirit of solidarity with an orientation toward quality products and services bring about changes that are best summed up in the phrase, "reinvent our future." Community building begins at home among the workers and then, to the extent that it is possible, among the consumers of their products and services. It may be as minimal as ensuring active and collaborative participation of the workers in decision making but it may also extend to other aspects of their cultural and communal lives as they reach out to the larger community. The spirit of solidarity in cooperatives calls for free adhesion and open membership, equitable sharing of resources, democratic management, regional and international cooperation. The cooperatives ensure their growth in and with the spirit of solidarity through continuing education.

The continuing search for cooperation. The pastoral letter of the U.S. Bishops on Catholic Social Teaching and the U.S. Economy cites, on a footnote to article 300 , a study on the Mondragon cooperatives to support its statement on greater productivity, job security, work satisfaction, and reduced adversarial relations, through cooperative ownership. It then suggests that this way of creating jobs and organizing work should be looked into with renewed interest.

Though interest in cooperatives is considerable, it is 
stymied by what appears to be the slow progress of the cooperative movement. Since the Pioneers of Rochdale, England, founded the first worker cooperative in 1844 and enunciated the principles that would guide their enterprise there has been a sustained interest in cooperatives but few remarkable advances such as those of the Mondragon group. Cooperatives are few and small compared to major of U.S. companies as may be noted from a comparison of the list of Fortune 100 companies and the list of the top 100 cooperatives in the United States not all of which are worker cooperatives (see Appendices C and D). The cooperative way of ownership and working together do not seem to come naturally; they have to be learned, and is one reason why cooperators emphasize continuing education.

The Mondragon experience. Fr. Arizmendiarrieta was cognizant of this fact (HC, 232) and the success of MCC may be attributed to its excellent school system that graduates both technicians as well as managers. When students get to the polytechnic school, they have an option to do a workstudy program that helps defray the cost of their education. The work portion of the program trains them in cooperative work and management while producing components for other cooperatives. Afterwards, should they want to pursue graduate studies abroad, they join a cooperative that seeks financing for their studies and searches the market for 
their skills. Others may decide to test an idea for a new enterprise and enter into contract agreement with Saiolan, the enterprise incubator, to assist them in translating their idea to reality. For those who need it, advanced studies in cooperative management is offered by Otalora, the center for graduate studies in cooperation. All these are phases of a curricular offering that any university can emulate. The example of the Mondragon University is a topic of Chapter 4 .

Success, however, brings new challenges. For MCC, it is global competition. The areas of manufacturing they are in are also the areas of big capitalist companies with huge resources. To hold their own, MCC cooperatives reorganized and gave a central body greater powers to plot and carry out global strategies. The drive for greater competitiveness, however, can mean more aggressive management policies that threaten the MCC value of equilibrio, or balance, between the interests of the cooperative and the well-being of the workers. The orienting function of education at the intersection of politics and socio-economics can be instructive and is elaborated in chapter 4.

\section{Delimitations of the study}

Given that both writers were prolific and given that this study is focused on the educational aim of one and the ethical aim of the other, it is inevitable that other 
important works did not get as much attention as Arizmendiarrieta's Pensamientos and Ricoeur's Oneself As Another. Furthermore, from these books, Chapter 5 of the former and Chapter 7 of the latter are given the most consideration.

Another limitation is derived from my reference to Ricoeur's narrative theory. This poses the need to outline the theory in some detail in Chapter 2 despite the sense of not doing justice to it. I refer the reader to the works of Ricoeur cited should the need arise to appreciate the fullness and precision that only Ricoeur can bring.

Finally, in this study I do not enter into the polemics that Ricoeur engaged in to contrast his position to that of other philosophers, for instance, the proponents of natural law or the proponents of explanation who are opposed and matched by the proponents of understanding. Instead I build on the reconciliations that Ricoeur brings to opposing camps or seemingly contradictory notions.

\section{Specific Terminology}

Analogy - The bond of meaning to meaning in a symbol.

Apportionment - The distinction of shares assigned to each individual in the system of distribution coordinated by institutions $(O A, 200)$.

Cognitive framework - The basic values, organizational objectives, and guiding principles that orient and give the leaders of an organization a sense of where they want to go (MM, 281). 
Concordance - The principle of order that presides over the arrangement of facts (OA, 141).

Configuration - The art of composition that mediates between concordance and discordance (OA, 141).

Cooperative - 1) The structure of shared ownership and responsibility in an enterprise for mutual benefit; 2) Technical competence organized for profit on the basis of and to promote friendship and "good dialogue" among its worker-owners.

Cooperative culture of MCC - Lived values of equality, solidarity, participation, and the primcy of labor over capital, guided by attitudes of openness, balance, future orientation, self-evaluation, intercooperation, toward objectives of jobs creation, employment security, human and social development, self-reliance, economic progress.

Cooperative ethics - The educated decision to live and work in solidarity, with and for others, to usher in just and humane institutions; the ethical aim of cooperators.

Cooperative living - The unfolding of life-in-community mediated by the narratives of its members.

Cooperative work - The engagement of people at community building through the production of goods and services.

Dialogue - 1) The sharing among peers of thoughts and feelings marked by honesty and active listening; 2) The co-creation of the world by participating in naming it (PO, 69).

Discordance - The reversals of fortune that make the plot an ordered transformation from an initial situation to a terminal situation $(O A, 141)$.

Discordant concordance - Characteristic of all narrative composition, it is the synthesis of the heterogeneous, accounting for the diverse mediation performed by the plot: between the manifold of event and the temporal unity of the story recounted; between disparate components of the action--intentions, causes, and chance occurrences--and the sequence of the story; and finally, between pure succession and the unity of the temporal form, which, in extreme cases can disrupt 
chronology to the point of abolishing it (OA, 141).

Education - The life-long process of discovering the connectiveness of life through interactions at home, school, work, and active retirement.

Educational aim - The overall orientation of formal and informal education, contrasted to educational objectives which lead to measurable behavior; in Arizmendiarrieta, the engagement of people through formal and informal education in settings where they can live and work in solidarity to usher in just and humane institutions.

Emplotment - The configuration of human events into a unified story, linking them so that there is a discernible beginning, middle, and end. It constitutes the dynamic identity and unity of the human individual.

Employment security - In MCC, assurance that a job will be available anyhwere in the complex, with retraining if needed.

Equilibrio - The balancing of interests and needs, of individuals and of the collective; the balancing of technical imperatives and financial needs of the firm with social objectives and the economic needs of members.

Ethics - The aim of an accomplished life; contrasted to morality which is the articulation of this aim in norms $(O A, 170)$.

Explanation - Denotes the claim of non-differentiation, of the epistemological continuity between the natural sciences and the human sciences (OA, 125).

Formal education - Planned and regulated schooling associated with the granting of degrees and diplomas.

Fusion of horizons (Gadamer: Horizontverschmelzung) - In the act of understanding a text, the reader belongs to both the experiential horizon of the work imaginatively, and the horizon of his action concretely.

Hermeneutics - 1) The manifestation and restoration of a meaning addressed to me in the manner of a message, a proclamation, a kerygma; 2) A demystification; a reduction of illusion. 
Humane institution - A structure of living together where the basic needs for food, clothing, shelter, health care, and education of each member are met through the protection of human rights and the practice of social justice.

Informal education - Learning that is going on in homes, workplaces, community halls, churches.

Integrative process - The work of composition which confers on the narrated story a dynamic identity; what is being told is precisely this or that story, singular and complete.

Interpretation - The dialectics of understanding and explanation; a work of understanding that aims at deciphering symbols.

Just institution - A structure of living together where the equality of each member is realized by the community through a system of apportionment.

Iife - In the ethicocultural sense, the person as a whole; an incipient story; an activity and a desire in search of a narrative.

Life plan - The integration of partial actions into a broader unity which may be referred to as the task or function of man as such(OA, 177).

Literary Criticism - A semantic examination of the concept of textual unity as a construct of language, pursued through phenomenological dialectic and hermeneutic exegesis.

Narrative - Part of a chain of speech by which a cultural community comes to be constituted and through which it interprets itself narratively (TA, 131).

Narrative intelligence - Practical wisdom; phronetic intelligence (e.g. storytelling) as it differs from theoretical intelligence.

Narrative event - That which seeks expression in narrative; the act of configuring.

Narrative identity - By linguistic convention, the identity of the character (OA, 141). 
Narratology - The rational reconstruction of the rules hidden underneath the poetic activity; a second-level discourse preceded by narrative intelligence which issues from creative imagination.

Openness - Admission of anyone with the requisite skills and training to the cooperatives; nondiscriminatory.

Plot - A synthesis of heterogeneous elements, of multiple events or incidents with the complete and singular history; the plot has the power of transforming the manifold happenings into a story.

Practical wisdom - Moral judgement in situation and the conviction that dwells in it tested by conflicts arising from the limits of human institutions.

Poetic act - The creation of a mediation between time as flux and time as duration.

Scientific - According to Maurice Lageux, we consider scientific only those intellectual results that both provide a satisfying explanation of phenomena that hitherto remain uninteligible and successfully resist attempts at Ealsification to which they are systematically and rigorously submitted (TA, 256).

Self-esteem - The reflexive movement through which the evaluation of certain actions judged to be good are carried back to the author of these actions (OA, 172).

Semantics - The science of the sentence, concerned with making sense, with the communication of meaning, and thus responds to the integrative capacity of language.

Semantics of action - The network of expressions and concepts which the natural languages supply us with in order to distinguish 'action' from simple physical 'movement' and from psycho-physiological 'behavior.'

Semiotics - The science of signs; relies on the capacity of separation of language into constitutive parts.

Shaping systems - Major policies, structures, and instruments of governance and management that provide the means for an organization's to attain its objectives (MM, 281).

Social action - According to Max Weber, there is social 
action when human behavior is meaningful for individual agents and when the behavior of one is oriented toward supporting or opposing the action of others.

Social Relation - When there is stability and predictability in social action.

Solicitude - Friendship marked by spontaneous benevolence and balanced between sympathy and responsibility.

Solidarity - Social friendship and civic commitment among groups and individuals that shape economic life (EJ, 34).

Story (Aristotle: mimesis praxeos)- The imitation of an action.

Symbol - A double-meaning linguistic expression that requires an interpretation.

Text - Any discourse fixed by writing.

Tradition - A living passing-on of innovation which can always be re-activated by a return to the most creative moments of the poetic composition; the key to the functioning of narrative models; the relation between sedimentation and innovation.

Temporal identity of a story - Something which endures and remains right across that which passes away.

Understanding (Verstehen)-Proclaims the irreducibility and specificity of the human sciences against the methods of the natural sciences (TA, 125).

Worker cooperative - An enterprise whose owners are the workers themselves with stipulations limiting the participation of non-member workers, in the case of MCC, to 10\%; contrasted to cooperative associations which are organized to take care of the common needs of capitalist owners. 


\section{CEAPTER 2}

\section{REVIEW OF IITERATURE}

\section{Introduction}

In the educational aim of Arizmendiarrieta and in the philosophy of Ricoeur there is an emphasis on action that attribute to a common source of influence which suggests that I can find complementarity between them. The common source is Emmanuel Mounier, a French philosopher who published Esprit in 1932. Arizmendiarrieta and Ricoeur, though they neither knew each other nor were aware of each other's works, were at one point in their lives both disciples of Mounier. Ricoeur credits Mounier for the innovative conjunction between person and community and the lesson of joining spiritual convictions to political positions. He also credits Mounier with the conception of involvement that allowed a "flexible connection between thought and action without separating them or mixing them together (LP, 9)." Ricoeur would later on explicate the connection between thought and action in his books and essays. We will review in some detail sections from the last three works of Ricoeur that are published in English, namely, Oneself As Another, From Text to Action, and The Philosophy of Paul Ricoeur, the last one containing 
Ricoeur's intellectual autobiography and his responses to important reviews of his works.

Arizmendiarrieta, on his part, taught his disciples that a thought must be expressed in words and words must lead to action, otherwise neither thought nor word would be worth anything (Pe, 393). He also cited in full agreement a statement of Mounier that the economic revolution must be moral and the moral renewal must be economic for both to take hold (HC, 748).

Arizmendiarrieta also expressed an understanding of time that Ricoeur elaborated in his major works. He wrote, "Between the memories of yesterday and the dreams of tomorrow are the responsibilities of today $(P e, 107), "$ giving importance to all three segments but especially to the realities of the present moment. People engaged in work meet their responsibilities in the context of an orientation of their enterprise that is guided by a reflection on their history and the pursuit of their dreams.

These perspectives on action over time and spirituality and economics shed light on the educational aim of Arizmendiarrieta which was never spelled out in a book. MY main source is Joxe Azurmendi who brought together an anthology of the reflections of Arizmendiarrieta that pertain to education and assigned it a chapter in the Pensamientos. Grouped under three subheadings that 
Azurmendi used to sort these statements, the thoughts of Arizmendiarrieta on education address the issues on learning and personality, learning and emancipation, and education and cooperation. The grouping was brilliant but must be taken in the context of an adaptation by Azurmendi. The effort was completed within the first decade after Arizmendiarrieta's death $(T U 1,7)$ and is an illustration of what Ricoeur referred to as the triple autonomy of text, namely, freedom from the original intentions of the speaker, freedom Irom the original circumstances that were shared by speaker and listener, freedom from the attitudes of the audience that shaped the delivery of the discourse. In the case of the Pensamientos, the last freedom was somewhat limited by the presence of the original audience, namely, the engineers who were then managers of the Caja Laboral Popular (Bank of the Working People) which commissioned Azurmendi to do the compilation. In other words, Azurmendi had at his disposal an ongoing interpretation of those events from the engineers and managers, whose interpretation may have influenced his grouping. We will review this text first, indicating in several places where Ricoeur complements the thoughts of Arizmendiarrieta.

\section{Arizmendiarrieta on the Educational Aim}

The few pages in the Pensamientos that are devoted to education do not do justice to the importance given to it by 
Arizmendiarrieta. A possible explanation is that many of his sayings that apply to education can also be classified under other headings of the book. Nonetheless education was central in the thinking of the founder and he regarded the cooperatives as extensions of the educational effort, that is, as centers for training and maturation of the many men and women that the new social order will need (MM, 256). While teaching at the polytechnic school, he translated his own thoughts on permanent education to action by continuing his education at the Diocesan Seminary at Vitoria the library of which offered a wide range of intellectual stimulation, displaying on its shelves publications in the major European languages. When I visited, an attendant informed me that new books have made the library different from what Arizmendiarrieta knew but that most of the volumes he read on economics, sociology, philosophy, and pedagogy, would still be there. We checked for Marx and Mounier and these were still on the catalogue.

\section{Being learned and being a person. Under this} subheading in the Pensamientos, Arizmendiarrieta teaches that learned persons are the new nobility and teaches that our being human is dependent on education. He distinguishes human nature from nature in general in that human nature is transformed by work and technology, by skills learned through an educational process that endows people with 
humanity and propels the progress of civilization especially when teaching emphasizes social and human values. He links education to the economy, observing that without education technologically advanced products and specialized services would not be available to buy or sell. He advocates equality in educational opportunities and the continuing availability of these opportunities. He regards the intelligence that God has endowed each person as the basis of equality $(P E, 183)$. This whole section finds resonance in Ricoeur who argues for "the mediating role of the other, required along the route from capacity to realization"(OA, 181).

Being learned and being free. Here the founder teaches that education is the indispensable element in the true emancipation of the workers because it socializes knowledge and knowledge is power in that it gives people the means to administer the rights they have. In view of this, the greatest enslavement is the lack of knowledge and it is, therefore, the grave responsibility of everyone to get educated as a safeguard against being at the mercy of someone from the outside. This education must happen on a massive scale because no one can improve the lot of the masses without the masses. The workers must position themselves to replace the bourgeoisie who replaced the aristocracy by getting better educated. This will happen 
through the acquisition of liberal education as well as of skills in science and technology, the catalysts that will usher in the workers with a new outlook.

Education is the foundation of the new social order, Arizmendiarrieta teaches, and the lack of educational opportunities is the worst legacy from earlier times, not the disparities in economic standing. Yes, the powerful have their vested interests that render them sclerotic, but what keeps the masses lethargic is inadequate education. The combination of vested interests that sometimes oppose economic development and education that is unsuitable to the needs of the community is the real cause of all troubles and the absence of momentum ( $P e, 198$ ).

Arizmendiarrieta observes that education is a Iong process and for everyone it began a hundred years before birth, perhaps more (Pe, 214). Human history is counted in thousands of years and overcoming the beasts in people takes time and effort. Education must begin early because the good fortune of tomorrow will depend on the classrooms that young people will have gone through, not the cribs of their birth. A better tomorrow can only be assured if the tender souls who will be the men and women of tomorrow are adequately prepared for it. Before they enter the world of work, young people must have a clear and positive social vision, otherwise they would be shipwrecks in their 
spiritual lives and traitors to the workers' movement.

Education and cooperation. Under this section, Arizmendiarrieta emphasizes the linkage between education and cooperation, referring to the cooperative movement as an educational movement that uses economics as a means of instruction. In this context, education as a didactic and existential process has to include a dose of conscience and the habit of work, making work and study go hand in hand. Then also opportunities for both work and study must be extended throughout life in order for communities to be adaptable and for cooperatives to be flexible with its workforce. This arrangement will put the human potential under the best of circumstances and will provide a stream of new ideas that are as important for the progress of the cooperatives as the installations of new machineries. Work and education must be tied together in the service of a progressive community for the good of the people ( $P e, 223$ ).

Work as part of the educational process is also noted by Ricoeur. The discipline of work, he concurs, is the first teacher of the universal man (TA, 327).

\section{Axizmendiarrieta and Economic Justice for AlI}

As was noted earlier the pastoral letter of the U.S. bishops on Catholic social teaching and the U.S. economy entitled, Economic Justice for All, cited a study on MCC and suggested that cooperatives be one of the options to be 
considered in addressing issues of justice, work satisfaction, and the general well-being of U.S. workers. The pastoral letter also summarized key tenets of Catholic social teaching that Arizmendiarrieta in one shape or another institutionalized in the structure of the cooperatives. I will review these tenets and, where applicable, refer to how MCC has incorporated them. A reader must bear in mind, however, that the cooperative structure itself is derived not from Catholic social teaching but from the pioneers of Rochdale who were Christian social thinkers on their own right. Having said that, the fact remains that Arizmendiarrieta was a Catholic priest who remained faithful to his office as assistant pastor of the parish of Mondragon until his death. He did represent the official church at the lowest level and preached Catholic teachings on social justice. When accused as being a "red priest" and threatened by the provincial governor with exile for preaching that workers have a right to strike, he cited official texts of papal encyclicals and of the Catholic University of Louvain to support his statements and told the governor that it was the bishop's prerogative to assign him wherever. His bishop stood by him and he was not removed from his parish (TU2, 36).

The Christian vision of economic life. The second chapter of the pastoral letter deals with the Christian 
vision of economic life and quotes from Mater et Magistra the basis for all that the Church believes about the moral dimensions of economic life: "The dignity of the human person, realized in community with others, is the criterion against which all aspects of economic life must be measured (EJ, 15)." This same passage was cited by the Pastoral Constitution of the Church promulgated in Vatican II. In view of this criterion, human beings are ends to be served by institutions which, therefore, must also promote the bonds of community and solidarity that are essential to the dignity of persons. Where institutions fail to do so, they must be questioned, challenged, and transformed.

The Christian vision stems from the life and teaching of Jesus which were passed on from one generation to the next by a community of believers until they were written into the New Testament. The early Christians interpreted with Jesus the Hebrew scriptures and, after the prophets of old, they condemned the use of religion to avoid the demands of charity and justice. In the story of the good Samaritan, Jesus portrayed the representatives of official religion as heartless in avoiding the wounded man and illustrated how compassion bridged the information provided by the scene and the action taken by the Samaritan. Knowledge evokes love but love is made real by action ( $E J, 24$ ).

At the end of the parable, Jesus addressed the man who 
sought a definition of neighbor and thus occasioned the story, "Who was neighbor to the robbers' victim?" The obvious answer is the Samaritan, the man who showed compassion. What is not so obvious in the story is that Jesus defined neighbor for the man in the ditch, by responding to the question with a question. It would seem that instead of getting a definition of neighbor, the man who asked was told how to be a good neighbor. To answer his question, he had no choice but to compare himself to the man in the ditch. To the man in the ditch, anyone who came to his aid was a neighbor, including the despised Samaritan. The man in the ditch could not afford to be prejudiced. He had to be color-blind. In fact he could not see; he was half-dead. In a state of total helplessness, he was open to the love of the whole human race. When Jesus said at the end of the parable, "Go, and do likewise," he enjoined all of us to answer the call to be neighbor, even to those who we think we ought to despise or ignore.

In a real sense every person comes into this world in a state of total helplessness similar to that of the man in the ditch. It is thanks to the mediation of a community that people become who they are. Thus the need to support the bonds of community and solidarity, advocated both by the educational aim of Arizmendiarrieta and analyzed as part of the ethical aim of Ricoeur. 
The pastoral letter next addresses the vocation of the Christian to be a disciple in community. "To be a Christian is to join with others in responding to this personal call and in learning the meaning of Christ's life (EJ, 25)." Early Christians in Jerusalem formed a community and shared their material possessions "so that there was no needy person among them(EJ, 28)." They held things in common, that is, they established among themselves mutual friendship and shared their concerns with each other in trusting relationships. Theirs was a community of hope, a sense of belonging to something new and forever open to the possibilities of God's plan into the future (EJ, 29). This new world in Christ "proclaims that God's creative love is constantly at work, offers sinners forgiveness, and reconciles a broken world (EJ, 30)." The bishops exhort those Christian communities which confront attitudes and ways of acting that promote injustice with words expressing hope that they will be strengthened by the power of the Risen Christ.

Christian life and justice. The second part of the chapter outlines ethical norms for economic life. Among the responsibilities of social living are the call to community in love and solidarity, the resolve to promote justice and participate actively, and action toward overcoming marginalization and powerlessness (EJ, 35). The pastoral 
letter distinguishes three forms of basic justice, namely, commutative, distributive, and social. Commutative justice calls for fairness in all agreements and exchanges; distributive justice requires that the allocation of income, wealth, and power in society take into account people whose basic needs are unmet; and social justice implies that persons have a right and duty to contribute to and take part in the life of society and that society must enable them to participate $(E J, 36)$. It declares that "Work with adequate pay for all who seek it is the primary means for achieving basic justice in our society (EJ, 37)."

Concerning the availability of work to everyone who wants to work, it is noteworthy that MCC has made the creation of quality jobs one of its primary goals. The 1996 Annual Report proudly announces that over 2,600 new jobs have been created $(A R, 6)$. Given the guarantees that MCC makes to its worker-members, these jobs are sustainable and takes into account the need of workers for active participation. MCC worker-members are members of small work units where they interact on a regular basis. They are required to vote in general assemblies and are expected to serve on committees without further remuneration.

\section{Arizmendiarrieta, Paolo Freire, and Liberation}

Among the books found in Arizmendiarrieta's bookshelf was Paolo Freire's Pedagogy of the Oppressed (MM, 256). 
Both authors have espoused the cause of the underprivileged and I find it relevant to review this work of Freire, particularly the third chapter which elaborates on dialogue as a human phenomenon and its relevance to education.

Freire's analysis of dialogue as a human phenomenon is probably his greatest contribution to contemporary thought in pedagogy. He begins by noting that there are two dimensions to the authentic word, namely, reflection and action. Reflection must lead to action and thus transform the world, for a word to be authentic. An authentic word is an interaction between reflection and action. One without the other leads to either verbalism, that is, senseless chatter, or activism, that is, action for action's sake.

A true word is communal at its roots; no one can say a true word in isolation. Dialogue is an encounter between men and women, "mediated by the world, in order to name the world. ... Those who have been denied their primordial right to speak their word must first reclaim this right and prevent the continuation of this dehumanizing aggression. ... dialogue imposes itself as the way by which they achieve significance as human beings (PO, 69)." BY speaking their word, by listening, and being listened to, people are transformed and thus begin to transform the world, since they are part of the world.

Dialogue is possible only in the context of profound 
love, humility, Eaith in humankind, hope that leads to the incessant pursuit of justice, and critical thinking which discerns solidarity between the world and people and regards reality as process. As a relationship between two responsible subjects, dialogue cannot exist in a relation of domination. "The act of love is a commitment to... the cause of liberation (PO, 70)." Dialogue that is founded on love, humility, and faith is a horizontal relationship which leads to mutual trust and hopeful openness to the incompleteness of the human order that calls for action, action that transforms the reality under the guidance of critical thinking (PO, 72-73).

Education that is dialogue-based seeks first the content of the dialogue. The teacher is to teach the student clearly what she gets from them confusedly, that is, she is to teach the objective situation and their awareness of the situation. "Utilizing certain basic contradictions, we must pose this existential, concrete, present situation to the people as a problem which challenges them and requires a response... at the level of action (PO, 76-77)." The investigation of the students" "thematic universe, " that is, the complex of their "generative themes" begins the dialogue between teacher and students. "[T] he object of the investigation is not persons (as if they were anatomical Eragments), but rather thought-language with which men and 
women refer to reality, the levels at which they perceive that reality, and their view of the world, in which their generative themes are found $(P O, 78) . "$ In this moment of reflection, they perceive "Iimit-situations which critical perception embodied in action leads them to attempt to overcome in a climate of hope and confidence, perceiving the limits as the frontiers of new possibilities, the untested feasibility implicit in that perception (PO, 80-83)."

Freire's methodology of thematic investigation as constitutive of dialogal education is an insight that is also found in Arizmendiarrieta whose study circles were moments of dialogue. What is not sufficiently analyzed is the humanization that happens in dialogue's listening moment. The teacher affirms students not only when she leads them to speak their word and opens her mouth in praise but especially when she leads the class to listen to the speaker. Listening that is characterized by unconditional acceptance is the liberating moment of dialogue. Freire refers to Malraux's interview of Mao who spoke of hearing out the peasants inferring thereby the virtue of listening. However, with Mao's agenda in mind, Mao's counsel may be seen as not primarily to accept the peasants but to transform them to his image and to use them against his enemies, in other words, for his political ends.

In contrast, the liberation that happens in dialogal 
education comes from the growth in self-understanding that is instanced by the encounter between teacher and class and the mode of listening that is promoted in those encounters. The growth that is brought about by the love of another human leads to an increasing awareness of one's possibilities for becoming more human.

Freire's insight into dialogue is invaluable and is an affirmation of Arizmendiarrieta's thoughts on it. The MCC experience itself is a testimony to good dialogue among members resulting in wholehearted participation as was noted in the action research conducted by Davydd Greenwood $(1989,160)$. Nevertheless, the effect of dialogue on growth in self-understanding in relation to the ethical aim is brought to new levels in the work of Ricoeur on the mediation of narratives. This is the thrust of Ricoeur's ethics.

\section{Ricoeur on the Ethical Aim}

During the last decade of his life, Ricoeur extended the study of language, of action and of narration by an investigation into ethics, morality, and practical reason (LP, 51). Toward the end of the sixth study of his last major book, Oneself As Another, Ricoeur explores the ethical implications of narrative to his study of the self and describes narrative self. In the seventh study he defines the ethical intention as the wish to live a good life with 
and for others in just institutions. He explains that there are three parts to this definition, each part adding to our knowledge of the self, for Ricoeur undertook the study of ethics as part of his probe into personal identity. The implication is that we know who we are by the ethics we hold, the norms we follow, and our exercise of practical reason. We identify ourselves in the choices we make from a myriad of possibilities that is presented to us in the dialectics between selfhood and otherness. This dialectics is expressed in narratives that take note of both our changing and our staying the same. The story of our birthdays, for instance, illustrates how we have changed through the years and yet we stayed the same persons. Ricoeur uses the phenomenon of character and the ethical notion of self-constancy to symbolize the two poles of the dialectics of personal identity and thus the two modalities of our permanence in time. Character is the perpetuation of the same, that by which we can be identified and reidentified; self-constancy is that manner of conducting ourselves so that others can count on us as persons.

Because someone is counting on me, I am accountable for my actions before another. The term "responsibility" unites both meanings: "counting on" and "being accountable for." It unites them, adding to them the idea of a response to the question "Where are you?" asked by another who needs me. This response is the following: "Here I am!" a response that is a statement of self-constancy (OA, 165). 
Narrative identity and the other. Between character and self-constancy lies narrative identity, the narrativised self which, in and through the movement that narrative gives, both resists "acquired dispositions and the sedimented identifications-with" that make up character and gives to the narration of self-constancy recognizable features of character that are loved or respected $(O A, 166)$. Narrative identity is the self interpreting its moment in time; it is the unfolding of the self. Ricoeur maintains that "Everything that is recounted occurs in time, takes time, unfolds temporarily; everything that unfolds in time can be recounted (TA, 2)." This functional unity of all narratives poses some problems because now we have to ask about those lines in literature that tells of the night of the soul, especially in the conversion narratives of science fiction and autobiographies, where the subject refers to itself as nothing. These narratives seem to suggest that the self refigured by narrative is at the same time confronted with the possibility of its own nothingness. Ricoeur notes that this nothingness is not the nothing of which there is nothing to say; in fact, there is much to say about who the $I$ is when. the subject says, "I am nothing." This I is "a self deprived of the help of sameness (OA, 166)" and in that deprivation the response to the question "Who am I?" refers not "to nullity but to the nakedness of 
the question itself (OA, 167)." "I am nothing" is an interpretive narrative of a deprived self declaring itself on the same level as the "Here I am" of the self responding to the other. This consideration enables Ricoeur to compose the two questions into "Who am I, so inconstant, that notwithstanding you count on me?" and to note that "the gap between the question which engulfs the narrative imagination and the answer of the subject who has been made responsible by the expectation of the other becomes the secret break at the very heart of commitment (OA 168)." Ricoeur further notes that "this secret break is what makes the modesty of self-constancy differ from the stoic pride of rigid selfconsistency" and that "the limiting cases produced by the narrative imagination is a dialectic of ownership and of dispossession, of care and carefreeness, of self-affirmation and of self-effacement (OA, 168)." This dialectic points to "the ethical primacy of the other than the self over the self" and "the complicity of this movement of effacement by which the self makes itself available to others" so that in "the 'crisis' of selfhood" self-hatred does not replace self-esteem (OA, 168).

This dialectic also provides the philosophical basis of Arizmendiarrieta's teaching of "To create but not to possess; to render productive but not to dominate" which now may be viewed in a light beyond its ascetic import, namely, 
in the consideration of the self addressed by the other.

In response to the other, the self steps out of the

confining hold of material goods and has the opportunity to prefer the other over other goods. Some examples may illustrate this reality. A sole proprietor intent on the continuation of his/her business is always haunted by the possibility of disability, death, and dishonest hirelings, whereas partners in a partnership are less so. Beyond the pooling of resources that the partnership realizes, the friendship among the partners we can cite another example here that will later on be explained at length and that is the response of people to the suffering of others in great disasters, helping other people at the risk of their own Iives.

This other who addresses the self may be the "thou" of the face to face encounter, or the anonymous "third party" who is the bearer of rights, or an inner voice. Ricoeur's further analysis of the other than the self yields to an "ultimate expression of otherness that haunts selfhood (LP, 53)," the voice of conscience, the source of which, he says, taxes philosophical investigation to its limits. Ricoeur wonders whether this voice comes from "a person who is other whom I can still 'envisage,' from my ancestors, from a dead god or from a living God, but one as absent from our life as the past is from all reconstructed history, or 
even from some empty place (LP, 53)." Where Ricoeur's philosophical speculation ends, the faith of Arizmendiarrieta extends, tracing the source of that voice to God and humanity ( $P e, 155$ ) and teaching that a dose of conscience as well as the habit of work should be part of education ( $P e, 219$ ). For Arizmendiarrieta work is never separated from conscience and his followers attest to this. "We could not be pure technocrats, who know perfectly the processes of chemistry or physics or semi-conductors but nothing more. ... [W] developed the idea that in order to do things we needed technical competence as well as spiritual witness and personal effort," Alfonso Gorroñogoitia admitted(MM, 245). He was chairman of the governing councils of Caja Laboral Popular (the MCC bank) and Fagor (the largest MCC factory) in the $80 \mathrm{~s}$.

Aiming at the good life. One response to the "voice of conscience" is our wish to live the good life with and for others in just institutions. But how do we discern the good life that we are aiming at? Ricoeur, following but improving on Aristotle, seeks "the fundamental basis for the aim of "the good life' in praxis (OA, 172)." Internal to praxis is a teleology that Ricoeur uses as the structuring principle for the aim of the good life. This teleology leads to a "hierarchical principle that would allow finalities to be included, as it were, one within another, 
the higher being the excess of the lower (OA, 173)." Put together by the anticipation of the narrative unity of life, this hierarchy can be seen from the viewpoint of its ethical integration under the idea of the good life (OA, 175). But the unifying principle of a practice, according to Ricoeur, Iies not in the logical relations of coordination nor in the role of constitutive rules in the sense of game theory and speech-act theory, which are ethically neutral. Rather it is to be found in the sphere of meaning opened by the notion of constitutive rules "in which appraisals of an evaluative (and subsequently normative) nature are attached to precepts of doing (something) well. The properly ethical character of these precepts is ensured by what MacIntyre calls 'standards of excellence,' which allow us to characterize as good a doctor, an architect, a painter, or a chess player (OA, 176)."

Ricoeur explains that these standards of excellence are rules of comparison related to the ideals of perfection shared by a community of practicioners; they "allow us to give sense to the idea of internal goods immanent to a practice, [which] internal goods constitute the teleology immanent to the action, as is expressed on the phenomenological plane by the notions of interest and satisfaction, which must not be confused with those of pleasure $(O A, 177) . " \quad$ And, just as partial actions are 
integrated in the broader unity of life plans, these internal goods may be thought of as brought together by each praxis.

With and for others: solicitude. The reflexive moment of the good life is self-esteem the unfolding of which is solicitude, the second part of Ricoeur's definition of the ethical aim. He defines unfolding as "a break in life and in discourse that creates the conditions for a second-order continuity, such that self-esteem and solicitude cannot be experienced or reflected upon without the other (OA, 180)"

The self is worthy of esteem by reason of its capacities and along the route from capacity to realization is the "mediating role of others (OA, 181)." Self-esteem, a virtue of one, supposes friendship, a virtue of mutuality which lends to a transition to justice, the virtue amongst many. Ricoeur refers to Aristotle who said that happiness is mediated by friendship and distinguished three types of friendship by its objective: for the sake of the good, of utility, and of pleasure (OA, 182)." on the ethical plane, Eriendship is a mutual relationship for the good and "this reciprocity extends all the way to the commonality of living together...[in] intimacy (OA, 183)." Mutuality in friendship, Ricoeur notes, borders justice but is not justice in that justice governs institutions and friendship defines interpersonal relations (OA, 184). 
Ricoeur also follows Aristotle on the elaboration of Eriendship where a friend is held to be "another self... who has the role of providing what one is incapable of procuring by oneself [and is therefore] the greatest of external goods (OA, 185)." The implication is that relative to having real friendship, all other goods are secondary. Aristotle's metaphysics provides occasion for another expression of the philosophical basis of the detachment from materials goods that Arizmendiarrieta teaches. Ricoeur also notes that in this metaphysics, friendship is an act, thus a becoming, thus a tending toward the actualization of power. Friendship in other words is filling something that is lacking and works "toward establishing the conditions for the realization of life, considered in its intrinsic goodness and its basic pleasure (OA, 186)." Friendship accentuates the good man's consciousness of the desirability of his life and leads him to a consciousness of the desirability of his friend's life.

Ricoeur calls the above exposé the ethics of reciprocity where the giving and receiving between friends are theoretically balanced. He considers the mutual character of friendship in Aristotle as "the midpoint of a spectrum, in which the end points are marked by inverse disparities between giving and receiving, depending on whether the pole of the self or that of the other 
predominates in the initiative of exchange (OA, 188)."

Where the self is summoned to responsibility by the other, Ricoeur notes a dissymmetry in that the self seems to be a passive "I." In an attempt to maintain the reciprocity of friendship, Ricoeur draws attention to the self's regard for others, a capacity for giving that is freed by the other's initiative. This capacity to give stems from goodness which in many languages, Ricoeur notes, means at once "an ethical quality of the aims of action and the orientation of the person toward others, as though an action could not be held good unless it were done on behalf of others (OA, 189)." The regard for others points to a benevolent spontaneity that distinguishes solicitude from mere obedience to duty, a spontaneity that is intimately related to self-esteem within the framework of the aim of the 'good life.' Ricoeur uses this notion of spontaneity to compensate for the dissymmetry in the initiative of the other in calling forth the self, in issuing injunctions. This spontaneity is also evoked by another dissymmetry, that of the suffering of the other, and is expressed as sympathy or compassion. In Ricoeur's philosophy of action, the other is both an acting and suffering being, and suffering is not defined solely by physical or mental pain but by the diminution of the capacity for acting, experienced as a violation of selfintegrity. The compassion we speak of here goes beyond 
simple pity in which the self is secretly pleased for having been spared the fate of the other. "From the suffering other there comes a giving that is no longer drawn from the power of acting and existing but precisely from weakness itself (OA, 191)." From the friend's weakness, the self is reminded of its vulnerability and its condition of mortality, giving rise to feelings of fear as well as liberation from this fear, the self receiving more than it can give. Ricoeur observes that there is an intimate union between the ethical aim of solicitude and feelings spontaneously directed toward the suffering other (OA, 192) and suggests that in this regard philosophy be instructed by tragedy, where the trilogy "terror," "pity," and "purification," cannot be classified under the subcategory of friendship for pleasure (OA, 191).

Thus whether the self is called to responsibility by the injunctions of the other, or called to sympathy by the suffering of the other, the self responds to compensate and realize the mutuality of friendship either through recognition of the other or through a shared admission of fragility and mortality. "It is this search for equality in the midst of inequality... [that] defines the place of solicitude along the trajectory of ethics. To self-esteem, understood as a reflexive moment of the wish for the 'good life,' solicitude adds essentially the dimension of lack, 
the fact that we need friends... (OA, 192)."

In just institutions. Ricoeur asserts that living well is not limited to the interaction among friends but extends to the life of institutions and that justice presents ethical features that are not contained in solicitude, namely, the requirement of equality. He proceeds to define institution as a structure of living together belonging to a historical community, irreducible to interpersonal relations but bound up with these primarily through a bond of common mores and only secondarily by some constraining rules (OA, 194). This bond of common mores is the basis of the community's power-in-common which stems directly from action in concert and the condition of plurality. "The idea of plurality suggests the extension of interhuman relations to all those who are left outside of the face-to-face encounter... and remain third parties... [which are] the inclusive midale term within the plurality that constitutes power (OA, 195)." Ricoeur links the plea for the anonymous with the fullest aim of the true life and observes that through the third party which includes the unknown from all generations, power receives its temporal dimension, both through the traditions of the past and through its ambition to last into the indefinite future. "Action, in its political dimension, constitutes the highest attempt to confer immortality, if not eternity, on perishable things. 
To be sure, power has its own fragility, since it exists only as long as people act together and vanishes when they disperse (OA, 196)." But "it is power, as wanting to live and act together, that brings to the ethical aim the point of application of its indispensable third dimension, justice (OA, 197)."

Ricoeur observes, however, that it is the sense of injustice that first sets thought in motion and leads us to penetrate the field of the just and unjust, "for justice is often lacking and injustice prevails. And people have a clearer vision of what is missing in human relations than the right way to organize them (OA, 198)." He looks into the analysis that Aristotle made into the polysemy of the just and unjust and recognizes at every stage the intersection of the private and public aspect of distributive justice (OA, 199). Noting that from Aristotle to the medieval philosophers to John Rawls the concept of distribution is closely tied to justice, Ricoeur opines that this concept must not be limited to the economic plane for it denotes "a feature fundamental to all institutions, to the extent that they govern the apportionment of roles, tasks, and advantages or disadvantages between the members of society (OA, 200)." He uses Rawl's terms in calling society a cooperative enterprise insofar as the shares distributed are proportioned among those who participate in 
it and declares that the conception of a society as a system of distribution transcends the terms of the opposition, individual versus society. As a system that distributes roles, Ricoeur reasons, the institution is something more and something other than the individuals who play these roles, that is to say, the relation is not reduced to the terms of the relation. Neither does the relation constitute a supplementary entity; it exists only to the extent that individuals take part in it, Ricoeur argues further. He then posits that "[a] distributive interpretation of the institution contributes to tearing down this wall [between the individual and society which wall prevents the transition from the interpersonal to the societal planel and assures the cohesion between the three componentsindividual, interpersonal, and societal-of our concept of the ethical aim (OA, 201)."

Ricoeur refers us next to the ethical core that is common to both distributive justice and reparative justice, namely, equality. He notes that, as in the unjust, the unequal is what we deplore and condemn. He observes with Aristotle that where there is sharing, there may be too much or not enough; the unjust man is one who takes too much in terms of advantages or not enough in terms of burdens. He further observes that Aristotle carefully marks out the type of intermediateness (the "middle of the road" position) that 
defines distributive justice, namely, proportional equality, holding that

Arithmetic equality is not suitable because of the nature of the persons and of the things shared. For one thing, in a society of antiquity, persons have unequal shares, related to unequal merits, which, moreover, different constitutions define in different ways; for another thing, the shares are themselves unequal outside of justice one might say, susceptible to brute division, as in war or pillage. Distributive justice then consists in equalizing two relations between, in each case, a person and a merit. It therefore rests on a proportional relation with four terms: two persons and two shares $(O A, 201)$."

The elaboration above, Ricoeur reminds us, is to gather together the lasting and convincing strength of the connection between justice and equality and not to know whether or not equality can always be defined in terms of the intermediate or the idea of proportional equality, both of which are "no more than secondary procedures for 'saving' equality, philosophically and ethically....The idea of fair shares refers back to the idea of belonging that extends all the way to that of an infinite mutual indebtedness...[and,] in the best hypothesis, to the idea that we find in Rawls of a mutual disinterest for the interest of others (OA, 202)." He summarizes with the statement, "Equality is to life in institutions what solicitude is to interpersonal relations.

\section{Ricoeur on the Ways of knowing}

Relevant to his investigation into ethics is a prior study on the ways of knowing, answering the question: What 
constitutes knowledge of the human reality? The considerations we will make here are important toward answering another question: How does one get to know truth and justice?

Explanation and understanding. In response to the questions above, we will follow Ricoeur's discussion on two methods of arriving at knowledge in the human sciences-one, called explanation, which denotes the claim of epistemological continuity between the natural and human sciences, the other, called understanding, which proclaims the irreducibility and specificity of the human sciences-and then consider at length the dialectics of these two which Ricoeur calls interpretation (TA, 125-6), our method of choice.

In the realm of the natural sciences, repeated confirmation of the same explanation despite systematic and rigorous attempts to disprove it establishes a measure of certainty of the explanation (TA, 256). That a similar feat can be done in the human sciences is the contention of the proponents of explanation but this is contested by the proponents of understanding and Ricoeur observes that this contest is played out in a very instructive way for our purposes in the theories of text, action, and history. In the theory of text we pose the question whether we get to know text through explanation, that is, through structural 
analysis and attention to form which is the intersection of codes set in operation by the internal workings of the text, or through intersubjective understanding, that is, through a communication between the soul of the reader and that of the author. As a starting point towards resolving the conflict, Ricoeur chooses semiology, the science and use of signs to which text analysis belongs, because it has developed explanations and models that are not borrowed from the natural sciences. These models are more often based on stable correlations between discrete units which contrast with the models of the natural sciences that are often based on regular sequences between events, stages, or phases of a process (TA, 128). Ricoeur notes that the theory of interpretation is confronted by semiological models, not natural models. We will follow Ricoeur's explication of his theory of interpretation in order to understand and use this method.

Theory of text. Among the many developments in semiology Ricoeur chooses and elaborates on the development in narrative because the narrative genre of discourse will help to establish the parallelism between the theories of text, action, and history. Narrative is discourse greater than a sentence; discourse itself being characterized by a "process of exteriorization that begins with the gap between saying and the said, continues through the inscription in 
letters, and is completed in the complex codifications of works of discourse, narrative among others (TA, 130)." The gap between saying and the said may be illustrated by the following observation. "The bread is tasty"; the bread is consumed and gone, but what was said in my saying remains. This is why it can be written and become text but, as written material, it drifts farther from the dialogic understanding made possible by the questions and answers of a conversation. As text, it is now governed by codes similar to the grammatical code that guides the understanding of sentences. Ricoeur observes that in the case of narratives, these codes are the same as those brought to light by structural analysis and are called narrative codes. Narrative achieves semantic autonomy, the necessary condition for the objectification of discourse.

Theory of action. Here Ricoeur (TA, 132-3) summarizes the contention of the proponents of understanding thus: We do not use the same language when we speak of occurrences in nature or of human actions: in the former we use words like cause, law, fact, explanation, and so on; in the latter we speak in terms of projects, intentions, motives, reasons for acting, agents, and so forth.

The battle has raged mainly over the use of the word cause, Ricoeur observes and explains that the fight was based on the wrong assumption that cause (causation) has 
only one meaning, namely, the one given by Hume. For Hume, Ricoeur notes, the relation between cause and effect implies that they are identifiable separately; there is no logical connection of implication between antecedents and consequences. The proponents of understanding note that this is not the case between intention and action, or between motive and project; a project cannot be identified without mentioning the action to be done nor can motives of an action be mentioned without referring to the action. They contend that only in this context may one speak of an agent being the cause of his action and certainly not in the context of a Humean causal model of a constant antecedent where an agent is detached from his action. There are two languages then, each with an equal right to respectability. Riceour contends that, no matter how conciliatory, the last statement is untenable and proposes two arguments to support his contention. Observing that in ordinary language the languages of causation and motivation interfere, he argues that what we are dealing with here is a scale whose two end points would be motivation without causation seen, for instance, in a game of chess or strategic models, where the motives are held to be reasons for making the moves, and causation without motivation seen in the ordinary experiences of constraints where a disturbance, a housefly on one's face for instance, rather than an intention causes 
an action. In this latter case, causal explanation is useful. Certain internal motives are close to this end of the scale, those that respond to the questions, What prompted him to do this? What made her to do that? Ricoeur points out that all Freudian-type unconscious motives are mainly interpretations in economic terms which are very close to causation-constraint. He then posits that the human phenomenon is somewhere between these two end points, "between causation that has to be explained and not understood and motivation belonging to a purely rational understanding. The properly human order is this in-between in which we constantly move, comparing our less rational and more rational motives, evaluating them relatively, submitting them to a scale of preferences and, finally, using them as premises in practical reasoning (TA, 134)." Ricoeur's second argument against epistemological dualism brings to the fore the fact that human action denotes bringing about changes in the world. He refers to Von Wright's system theory (humans can only conceive of a closed, partial system where action takes place) and observes that "there is no system without an initial state, no initial state without intervention, and no intervention without the exercise of power. Acting is always doing something so that something else happens in the world (TA, 135-7)." To balance this causal explanation, Ricoeur 
further observes that there is no action without the relation of knowing how to do something. "Causal explanation applied to a fragment of world history goes hand in hand with recognizing and identifying a power that belongs to the repertoire of our own capacities for action (TA, 137)."

Theory of history. Here Ricoeur calls attention to the specific competence that historical understanding involves, namely, the ability to follow a story. "Following a story is an activity that is entirely specific, by which we unceasingly anticipate a subsequent course of events and an outcome and adjust our anticipations as the story progresses, until they coincide with the actual outcome. Then we say we have understood (TA, 141)." He further notes that what allows us to continue to follow a story is explanation, which is the historian's intent to interpose a law in a narrative so that understanding is set in motion. The interplay between understanding and explanation is similar to what has been noted in the theory of text and the theory of action which similarity is to be expected since "history combines the theory of text and the theory of action in a theory of the true narrative of the actions of those of the past (TA, 142)."

Ricoeur has two conclusions from all these considerations. First, we get to know about ourselves 
through the sciences of interpretation which combines the two moments of methodical explanation and nonmethodical understanding. The latter "precedes, accompanies, concludes, and thus envelops explanation. Explanation, in turn, develops understanding analytically (TA, 142)." He notes that this dialectical relationship between explanation and understanding results in a complex and paradoxical relation between the human sciences and the natural sciences.

Neither duality nor monism, I should say. To the extent that the explanatory procedures of the human sciences are homogenous with those of the natural sciences, the continuity of the sciences is assured. However, to the extent that understanding contributes a specific component-in the form of the understanding of signs in the theory of texts, in that of the understanding of intentions in the theory of action, or in that of the competence to follow a story in the theory of history-to this very extent, the discontinuity between the two regions of knowledge is insurmountable. But discontinuity and continuity are constituted between the sciences just as understanding and explanation are within the sciences (TA, 143).

His second conclusion touches on the ontological conditions of the dialectic between explanation and understanding. "Understanding testifies to our being as belonging to a being that precedes all objectifying, all opposition between an object and subject. ... [Understanding] both denotes the nonmethodical pole... in every interpretive science and constitutes the index... of the ontological relation of belonging joining our being to beings and to 
Being (TA, 143)." But, in order to avoid reconstituting the dominion of pure understanding, "philosophy must also be capable of accounting for the movement of distanciation through which this relation of belonging requires the setting up as an object, the objective and objectifying treatment of the sciences, and hence the movement through which explanation and understanding call for one another on the properly methodical plane (TA, 143)." 


\section{CHAPTER 3 \\ INTERPRETATION AS METHOD}

From the preceding review of literature we have followed Ricoeur's description of interpretation as the interrelation of understanding and explanation. We will now look into interpretation as the method used in this study. After a description of Ricoeur's philosophical tradition, we will make some observations on how the method is used by Ricoeur and proceed to describe how the method is used in this study.

\section{The Philosophical Tradition of Ricoeur}

Ricoeur explains his philosophical tradition in his essay, On Interpretation (TA, 1), as characterized by three features, namely, reflexive philosophy, Husserlian phenomenology, and the hermeneutic variant of phenomenology. Reflexive philosophy seeks self-understanding as the subject of the operations of knowing, willing, evaluating, etc. "Reflection is the act of turning back upon itself by which a subject grasps, in a moment of intellectual clarity and moral responsibility, the unifying principle of the operations among which it is dispersed and forgets itself as subject (TA, 12)."

With Husserl Ricoeur maintains phenomenology's 
fundamental insight, namely, intentionality. Consciousness is consciousness of something and if the self is conscious of itself, it is in the context of the world that the self lives in. The thinking self then is a consciousness-in-theworld. The hermeneutic variant of this insight says that consciousness configures the many meanings that the world presents through narrative, for anything that happens in time can be narrated and anything that can be narrated happens in time $(T A, 2)$. Narrative takes advantage of two ways of knowing, explanation and understanding.

Linking explanation and understanding. We saw in the debate between the scientific method of explanation and the philosophical method of understanding regarding human sciences that Ricoeur avoided the epistemological break advocated by the proponents of understanding and built a bridge between the two camps, capitalizing on an insight into the process of interpretation where explanation and understanding are but relative moments (TA, 126). Therefore, to the question, How do I get to know about me? Ricoeur would point to the method of gathering physical, socio-economic, and psychological data as the methodical moment that combines with the nonmethodical moment of understanding signs, intentions, and the competence to follow a story; which understanding "precedes, accompanies, concludes, and thus envelops explanation (TA, 142)." 
Philosophy is concerned with understanding because "it testifies to our being as belonging to a being that precedes all objectifying, all opposition between an object and subject." But, as was noted earlier, philosophy should also account for "the movement of distanciation through which this relation of belonging requires the setting up as an object, the objective and objectifying treatment of the sciences... In a dialectical manner, explanation must develop understanding analytically, lest understanding once more reconstitute the dominion of pure understanding at a new level of radicality. They call for one another on the properly methodical plane (TA, 143)."

Interpretation as method. As the dialectics between explanation and understanding, interpretation as method is dynamic and attended to by an abundance of meanings that the consciousness of the self-living-in-the-world presents, which meanings it is tasked to unveil in their fullness. To interpret is to organize words, sentences, and paragraphs to express the components of a relationship we want to analyze using the above mentioned dialectics. Interpretation is mediated by language, narrative discourse in particular. For instance, my understanding of the human reality is evident to me partly through the narratives I have developed about me and more abundantly by the narratives of my culture, narratives that preceded me, accompany me, and will 
mediate the conclusion of my story. These narratives are contained in the public records of my society: history books, the works of philosophers and scientists, classical and modern literature, the bible and other church documents, everything that can be found in a library. To illustrate this method we will follow Ricoeur's elaboration of narrative identity in the context of narrative theory. We have earlier reviewed narrative identity in relationship to the other as a prelude to Ricoeur's study of the ethical intention but did not remark on how he uses the method of interpretation. The following will serve the purpose of illustrating the use of interpretation as method as well as develop further the concepts that will be used in the next chapter.

\section{Ricoeur Using Interpretation As Method}

We can observe with Ricoeur that everything that happens in time can be narrated, and everything that can be narrated happens in time. This observation is the basis of what Ricoeur terms the functional unity of all narratives $(T A, 2)$. It also leads us to an understanding of the unity of the human person as the source of narrative and the relation between narrative identity and personal identity. This insight is an illustration of the human capacity to see connectedness in life, the ability to follow a story, and is the understanding moment of interpretation, the 
nonmethodical moment. This moment is followed by explanation, the properly methodical moment, and Ricoeur uses language analysis. Throughout his work at interpretation, Ricoeur weaves back and forth between the moments of explanation and understanding.

\section{Narrative theory and personal identity as dialectics}

between selfhood and sameness (OA, 140-151). Ricoeur elaborates on narrative identity by first confronting the problem of personal identity expressed in the polarities of identity as sameness and identity as selfhood. When he speaks of sameness, he refers to permanence that belong to people and is contained in two expressions, namely, character and keeping one's word. Ricoeur defines character as the set of distinctive marks and lasting dispositions by which an individual is recognized again and again. What gives history to character is habit, both as acquired (sedimentation) and as being formed (innovation), a dialectics of its own. The acquired set of identification are the values, norms, heroic figures, of the community we belong to and to which we have been socialized. Ricoeur observes that an element of loyalty is thus made part of our character as we seek to maintain ourselves in this acquired set of identification.

In the above analysis, Ricoeur uses data from the common usage of language, codified in its lexicon and 
grammatical rules. The words 'character,' 'habit,' 'sedimentation,' 'innovation,' are all found in the dictionary and the meaning that people attach to them can be objectively analyzed. This is the explanation moment of interpretation. To see their interrelationships and putting them together into the sentences above is the understanding moment of interpretation. Once put together, they become on a new level, themes for explanation. Let us proceed with Ricoeur's elaboration of narrative identity.

The other model of permanence in time is that of keeping one's word once it is given. Keeping one's words expresses self-constancy. Ricoeur observes that the continuity of character is one thing, the constancy of friendship is quite another. Confronted by death, this constancy seems to challenge time, a denial of change and, therefore, a separation from sameness. The promise to hold firm supposes an ethical justification which can be derived from the duty to safeguard language and to respond to someone's trust in our faithfulness.

Character and the plot. The dialectic of selfhood and sameness is the major contribution of narrative theory to the constitution of the self $(O A, 140)$ and the point of disclosure of narrative identity. By narrative we mean discourse greater than a sentence and the narrative event itself is defined by its relation to the act of 
configuration. When I narrate, I configure, that is, I put together events according to a plot and participate in "the unstable structure of discordant concordance characteristic of the plot itself(OA, 142)." The plot is a source of discordance inasmuch as it brings new elements and a source of concordance inasmuch as it allows the story to move forward. Emplotment is the configuring act by which human beings arrange events into past, present, and future in relation to a plot, as a storyteller would put to a story a beginning, a middle, and an ending. One paradox of emplotment is that it inverts the effect of contingency into the effect of necessity. After the appearance of the new which may not have happened or may have happened differently, a narrative necessity arises and what could have been becomes what had to be.

Ricoeur shows how the character of a story is itself plot by which we recognize the same story as it unfolds. In the spectrum of meanings between selfhood and identity, character represents sameness, where selfhood is identified and reidentified. At the other end of the spectrum, selfhood is distinct from identity and Ricoeur represents it by the ethical notion of self-constancy. By this construct of polar oppositions between character and constancy, Ricoeur demonstrates how the notion of emplotment mediates the diverse events in human life into a unified story and 
constitutes the dynamic identity and unity of the human individual. He also highlights the properly ethical dimension of selfhood (OA, 165).

The self and the ethical aim. Following the method above, Ricoeur places narrative theory at the crossroads of action and morality, making narration the natural transition between description and prescription implied in the two-fold connotation of the intuitive idea of mores, namely, that which is considered to be good and that which imposes itself as obligatory $(O A, 170)$. These connotations provide the distinction between ethics and morality, the first being teleological (therefore, Aristotelian) and the second deontological (therefore, Kantian). Ricoeur establishes between the two traditions a relation of complementarity (ethics must pass through the sieve of the norm) and subordination (the primacy of ethics; a recourse to aims in case of impasse in the application of norms).

\section{Using Ricoeur's Philosophical Tradition \\ Using the triple autonomy of text as basis. The act of} abbreviating the thoughts of Arizmendiarrieta for the purpose of portability and providing food for thought to the succeeding generations who are charged to ponder on the course of the cooperatives is an instance of what Ricoeur terms as the triple autonomy of text, text being defined as the fixation of discourse by writing, and discourse defined 
as speech greater than a sentence. As text, human discourse is freed from the original intentions of its author made known through the instantaneous clarification that is the privilege of dialogue; freed from the common circumstance that attended the speaker and listener which circumstance shaped the meaning of the discourse; and freed from the original dispositions of the listeners that played into the shaping of the discourse. The original intentions of the speaker, the original circumstance common to both speaker and listener, the original dispositions of the listeners-all these are lost to the readers because discourse is a temporal phenomenon. We replace these with our imagination, informed by codes embedded in the written narrative, codes that are the object of the science of signs, also known as semiotics. Text, objectified in this manner by semiotics, provide the data that meet the standards of scientificity, that is, they can withstand a systematic and rigorous attempt to falsify them (TA, 256).

I regrouped the quotes in the anthology that Azurmendi compiled under the chapter title Education into three sectors corresponding to the zones of intersection of the circles of ethics, politics, and socio-economics that Ricoeur drew. This operation is similar to what Azurmendi did, extracting these quotes from the many articles that Arizmendiarrieta wrote but which he never attempted to 
compile into a book. Guided by familiarity with the issues that Arizmendiarrieta addressed in his time, Azurmendi highlighted these statements by extracting them and grouping them into the text of the Pensamientos addressing the issue of education.

By regrouping the quotes that Azurmendi assembled, I enhanced their portability by extending portability to the quotes themselves, not just through the size of the book. I have done what a thoughtful reader who is familiar with the history and accomplishments of the Mondragon cooperatives would have done and what in fact Azurmendi has done. The attempt to find a unifying principle among the quotes obviously introduced my interpretation in a manner similar to how historians introduce their interpretations by the choices they make among myriad historical events and the arrangement of those events into a story. The resulting narratives provide content for a continuing reflection on what I suggest should be called cooperative ethics.

Interpreting the texts. Employing the phenomenological hermeneutics of Ricoeur, the anthology of Arizmendiarrieta's thoughts on education are interpreted in the light of education's directive function in the domains of ethics, economics, and politics. A world is allowed to emerge in front of the texts, a world that leads to new possibilities of being. The interpretation is explicated through these 
two moments: 1) from understanding to explanation and validation suggested by the texts of the Pensamientos and 2) from explanation and validation of text to understanding.

\section{Background of the Researcher}

My short story. I studied existential phenomenology in the mid-60's under the direction of Belgian professors who were for the most part graduates of Louvain University. Freedom and determination were two of many opposing notions we sought to bring together. In this particular case, the opposing notions were placed in a dialectical relationship and made into one notion, that of freedom-in-determination, and we used it to describe the human condition.

In 1970, when Ricoeur went to teach in Louvain, I was en route to Ethiopia to teach methods in a teacher training institute. On the plane were other teachers, one of whom, also a philosophy major, became my wife. Our sons followed suit. The first studied philosophy to support his law studies. The second, a son named after me, studied philosophy and earned his bachelor's degree from Louvain University at age 18. It was while he was a student at Louvain that the family made a trip to Mondragon to visit the enterprises inspired by a priest who also wanted to study at Louvain but could not because of the Nazis. Getting to know Fr. Jose Maria Arizmendiarrieta through his writing and those of his associates inspired me to go back 
to school and in fact did so by attending some classes at Louvain. But then the family moved back to the United States and settled in San Diego where I promptly embarked on my doctoral studies with the aim of contributing toward a college-level curriculum on cooperative ethics.

My namesake did the same at the master's level and we talked about coordinating our energies in curriculum development. However, our dream of collaborating at the School of Education was drastically modified on the eve of New Year's Eve, after a mere semester, when he died in a car accident. At his funeral mass at Founders' Chapel, I read the first lines of a song he wrote:

I don't know how it happened, but I'm happy that it did Suddenly I can smile at my clouds, whistle in the rain, be a little kid

and pondered on how the contradictories "death" and "happiness" could be brought together. I did not have to ponder for long. Fourteen days after the accident, Prof. Mary Abascal-Hildebrand called to offer me a graduate assistantship with the purpose of writing a syllabus on democratically-inspired organizational change which I accepted. Through her, Mondragon was introduced that summer to the University of San Diego (USD) and the following two summers saw USD graduate students go to Mondragon on study trips. In turn, she introduced me to the ethics of Ricoeur 
and challenged me to put him and Arizmendiarrieta together in a doctoral study.

My own study of cooperatives, I thought, would still be incomplete unless I was able to live in a kibbutz. This unique form of cooperative has the highest level of integration. My wish was granted in August, 1997, under circumstances so favorable, I could not have arranged them myself. These events and those of the recent past when regarded with narrative theory in mind and with how emplotment transforms human events, did indeed undergo inversion as to their effects from contingency to retrograde necessity. As a result part of my story now fulfills a collaboration with a little kid who whistles in the rain, one who can wring happiness from death's pain.

I still see many contradictions in life that need resolution, opposing pairs like wealth-poverty, profitability-solidarity, ownership-detachment. The last pair has been resolved for me by the power of example which precedes the power of thought as I ponder the life of Arizmendiarrieta aptly described by these words: "To create but not to dominate; to render productive but not to possess."

My interest in the compelling story of Mondragon. I began studying the Mondragon group of cooperatives in 1989 and visited them in 1992, 1996, and 1997. I marvel at how 
all this happened within the last 41 years. From the time the first cooperative opened its doors in 1956, MCC grew Erom 23 to 30,000 workers. Its annual sales amounted to $\$ 4.3$ billion in 1996 and its bank now administers funds in excess of $\$ 5$ billion ( $A R, 4-52)$. Equaliy interesting to me is the gestation period of 15 years prior to the opening of the first cooperative, during which time the youth of the parish of Mondragon gathered around their assistant pastor to learn both religion and sociology in the context of Catholic Action's three-step method: see, judge, act (MM, 30). What was even more important, they learned to trust each other and acquired a certain detachment from the wealth they would eventually create, while they mastered the skills that would make them the excellent engineers and managers that they became (MM, 245). They had the advantage of experiencing this trust given to and given by Arizmendiarrieta who showed unconditional faith in them (TU2, 13). They were also privileged to witness the detachment from wealth exemplified by the bicycle-riding Arizmendiarrieta who died without laying any claim to the bank he created almost singlehandedly (TU2, 37).

The Mondragon experience illustrates to me the centrality of education in any community development. Fr. Jose Maria came and met his future associates in 1941 when they were barely 15 years old. Risking non-comprehension on 
their part, he spoke to them of the ideal of making Mondragon a model for the industrialized cities of the province of Guipuzcoa ( $P e, 1)$. After organizing a sports team, he opened a polytechnic school that took in its first twenty students in $1943(M M, 30)$. Eleven of this first class accepted the challenge of a correspondence course in engineering that $\mathrm{Fr}$. Jose Maria arranged for them through the University of Zaragosa, while they worked in a local foundry and continued meeting with Fr. Jose Maria in sessions that focused on "discussions of conflicts between labor and capital, reform of private enterprise, and selfmanagement and the participation of workers in ownership (MM, 33)." of these, five eventually founded the first cooperative, making stoves. Today the polytechnic is one of Spain's best engineering schools and has recently merged with a teacher training college and a school of business to become a university.

Being a graduate of a Catholic university in the Philippines and currently going to one near the Mexican border, I cannot help but see the need for the involvement of Catholic parishes and universities in community development. The example of the parish of Mondragon, the schools it evolved, and the cooperatives that issued from them, are uppermost on my mind when I think of a universitydriven community development. Such an involvement is urged 
by numerous papal encyclicals and pastoral letters by national conferences of bishops such as those of the United States, Mexico, and the Philippines. As was cited earlier, the Pastoral Letter on Catholic Social Teaching and the U.S. Economy of the U.S. Bishops cites, on a footnote to article 300, a study on the Mondragon cooperatives to support its statement on greater productivity, job security, work satisfaction, and reduced adversarial relations, through cooperative ownership. I assume the bishops are aware that the Mondragon network of cooperatives grew out of a parish school and that the network is still growing because of that school. I submit that, given the right combination of adequate interest and funding, the experience can be duplicated by other universities. My hope is that this study will contribute in some way toward generating sustained interest. 


\section{CHAPTER 4}

\section{THE ETHICAL AIM FOR COOPERATORS}

The arguments presented in this chapter derive from an observation of the parallels in the educational aim of Arizmendiarrieta and Ricoeur which contribute to a definition of the ethical aim of cooperators. The ethics is further defined through an analysis of its three components, in the manner of Ricoeur. My reflections on the directive function of education in the domains of ethics, socioeconomics, and politics are guided by the reconfigured quotes of Part I, Chapter 5, of Pensamientos (Azurmendi, 1983 ) and serve to amplify the definition.

\section{Definition of the Ethical Aim for Cooperators}

Gleaning from Ricoeur's ethical aim on the one hand and the educational aim of Arizmendiarrieta on the other hand, the ethical aim of cooperators may be defined as the educated decision to live and work in solidarity with and for others toward the creation of just institutions.

Following the format that Ricoeur used in his presentation of the ethical intention, I distinguish three parts in this definition. The educated decision to live and work in solidarity is the first part. This decision is a result of both informal and formal education and is a 
response to the experience of care. From the earliest stages of life, the human person experiences care packaged as education, in home and school settings. The daily news, every now and then, calls our attention to exceptions and they shock us because of their aberration from the norm. But, for the most part, education is experienced as care and our response to that care is part of what may be called a fundamental moral experience. I will elaborate on this phrase which is borrowed from Maquire and Fargnoli (1996) in the context of the basic community.

The whole of society is a cooperative says Ricoeur, citing Rawl, to the extent that it practices distributive justice. But Ricoeur, and Plato before him, notes that what brings justice to our attention in a compelling manner is injustice. Our empathy is provoked by the suffering of the other. This empathy is accentuated if a caring relationship existed with the one suffering the injustice. The capacity for empathy presupposes an experience of both caring and being cared for and for most of us this experience was afforded us by the basic community of immediate and extended family and/or close friends. They provide the contexts of informal education. Thanks to this education, people are enabled to have empathy, the fundamental moral experience. The educated decision to live and work in solidarity is a specification of Ricoeur's good life. Recall that the 
good life in Ricoeur's definition of the ethical aim is a horizon, a limit idea which derives its meaning from our act of appraising, of evaluating all that we do, and includes some distant ideals of what is good emanating from selfesteem and made precise in praxis. These distant ideals are made specific in our definition of cooperative ethics and further translated to include worker participation in ownership and decision-making, democratic management, solidarity in pay, job security, and continuing education. Formal schooling gives depth to the decision to live and work in solidarity. As the cooperators gain ever deeper understanding and broader skills needed for working together, the sense of belonging heightens as their appreciation for each other's skills and persons become more evident. Personal interest is matched with communal need and opportunities are made abundant to develop those interests into marketable skills in the forms of service and the production of goods.

To work and live in solidarity is a step farther than the recognition of the communal origins of the human person. This part of the definition of cooperative ethics is midway between the first and second part of Ricoeur's definition, a mix of the good life and solicitude. This specification of the good life recognizes the embeddedness of people in their community. Life is good because family gives an abundance 
of meaning to it. Life is good because I enjoy working with my closest friends. Solicitude is inward-looking and a feeling of ownership for the group is a condition for survival. Friendship is governed by reciprocity but little attempt is made at achieving parity. There is an unspoken understanding that "what is mine is yours and what is yours is mine." At the workplace this is experienced in the ownership of the team project.

Work is an expression of togetherness as well as a production of marketable goods and services. Goods and services stimulate and improve the capacity of the human community for greater diversity at the workplace. Work is the main conduit of change. The phenomenology of change is a study of human action and Ricoeur, in agreement with von Wright, has opined that "the concept of intervention is truly what seals the union between the intentional component and the systemic component of action...(LP,347)" In von Wright's model, acting is always doing something so that something else happens in the world. Change implies movement and, therefore, has bearing, creates direction in one's life. Consequently work is never neutral. It is an ethical decision. The cooperators' recognition and acceptance of this aspect of work and the connectedness of their lives is part of their educated decision.

To sum up our reflections on this part of the 
definition, a cooperator, through formal and informal education that is conceived so broadly as to encompass all of life, moves from desire to an educated decision and to specifying the good life into living and working in solidarity. Living and working in solidarity is a major part of the good life which we recall is derived from praxis. Cooperative work is a specific praxis that has an immanent good whose appraisal is expressed in terms of standards of excellence. Nonetheless work is a praxis with a broad scope as we shall see from the world that emerges from the text of Arizmendiarrieta's thoughts on education. The second part of the definition, with and for others, is not a repetition of the notion of solidarity. Nor does it include all of Ricoeur's broad range of relationships on this part of his definition. They are face-to-face relationships but the reciprocity of obligations border on justice and often dwell on justice. Here, solicitude is directed outside the basic group but is affected by the dynamics within the basic group. It is a face-to-face relationship but one characterized by an arms length handshake. Solicitude is motivated by reciprocity with a desire for parity. Spontaneous benevolence is less frequent than in the basic community.

The third part of the definition of cooperative ethics is where we leave Ricoeur behind except for his insights 
into the anonymous other. The cooperative is a just institution in the making in that it attempts daily to practice all three forms of justice: distributive, commutative, and social justice. The assumption is that there is always room for improvement in the cooperatives' practice.

The main thrust of this part of the definition, however, is that the cooperative is oriented towards realizing the reign of justice everywhere. The cooperative is not free to deal with crooks on the pretext that a transaction is "purely business." Business transactions, inasmuch as they are human actions, are never ethically neutral and the cooperative must always be aware that injustice outside the walls is a threat to justice inside the walls.

This orientation of cooperatives toward creating just institutions may be deduced from the principles enunciated by the International Cooperative Alliance (see Appendix B). More importantly for this study, it is gleaned from the Pensamientos with the assistance of Ricoeur. The narratives of Ricoeur's ethical aim and Arizmendiarrieta's educational aim may be construed as narratives of liberation. One can see the pattern of deliverance from one situation to a better situation through a mediator. In Ricoeur it is the deliverance of the self from incapacity to capacity through 
the mediation of the other of the face-to-face encounter as well as of the anonymous other of just institutions. In Arizmendiarrieta it is the deliverance of a community from idleness or unemployment to full engagement through the mediation of an educational system that includes a network of cooperatives.

Arizmendiarrieta envisions a society where education, as the first enterprise of the community, mediates the unfolding of the human potential on the road to actuality. Education is the first expression of caring given by a community to its members and provides the basic moral experience of how it is to be cared for and how to care in turn. This mediation happens in the broadest possible context of life but it takes place especially in the classroom and in the workplace. The primary lesson to be learned in both these places is to live and work in solidarity, in other words, to engage each other in the creation of the social bond by which we hold ourselves personally responsible for the common good and, therefore, personally engaged in its furtherance.

Ricoeur complements Arizmendiarrieta when he contrasts this notion of mediation to the notion from natural law which states that the human being is endowed with rights and privileges even before he/she participates in the burdens related to perfecting the social bond (OA, 181). Ricoeur 
refutes this argument and its implication on political theory which would endow an "individual" with rights that are not consequent to his/her commitment to society.

Cooperative Ethics, Education, and the Domains of Economics and Politics

I shall now amplify this definition by relating it to a rearrangement of the quotes on education in the Pensamientos and to another work of Ricoeur, namely, on Ethics and Politics (TA, 325). As was noted in Chapter 1, in this essay Ricoeur used three circles to illustrate the intersection of ethics, politics, and socio-economics. Each has its own center of interest but there are areas of overlap which he termed zones of confrontation and intersection implying that in these zones the human community is at its creative best. The state, defined as "the organization of a historical community" for the purpose of making decisions (TA, 330), fits the billing of a cooperative, given certain adjustments as was noted earlier.

\section{Interpretation at the intersections of domains.}

Ricoeur distinguishes between society and community, the former being the economic mechanism and the latter the exchanges marked by the history of mores and customs $(T A, 327)$. From the comparison between economics and ethics he aims to derive the means of determining what is specific to politics in order to better contrast it to ethics in turn 
(TA, 325). His thesis is that politics must first be defined in relation to economics before being confronted by ethics.

The intersection between economics and politics is marked by the modernity that states acquire "wherever there is a society in which labor is organized with the aim of a methodical struggle of man against nature (TA, 327)." This struggle, joined to the primacy accorded to calculation and efficiency, is also at the intersection of ethics and economics as the struggle "tends to become the new form of the sacred, if it does not abolish purely and simply the difference between the sacred and the profane (TA,327)." As competition leads to the division of society into groups, levels, and classes, which division "maintains the isolation and insecurity of the individual delivered over to the social apparatus," a feeling of injustice arises. The modern man is "placed at the crossroads of the economic and the political and suffers from the logic of industrialization and the old rationality belonging to the political experience of peoples (TA, 329)." To the modern man, labor "appears at once as technically rational and humanly unreasonable (TA, 328)." To flee this contradiction, he turns back to private life, "seeking survival in the 'privatization' of happiness (TA, 329)." He finds no meaning in the simple struggle against nature and 
he works merely to gain leisure time. Work in modern societies "has ceased to be the great educator in the ways of rationality that Hegel and Marx saw it as (TA, 329)."

To restore the educative function of work, I propose to designate the fourth sector, where all three circles intersect, the privileged place of education as the primary activity of the human community. Ricoeur himself assigned education to one of the roles of the state which is the domain of politics. However, economics as Hegel, Marx, and Arizmendiarrieta would have it, is also engaged in education. So does ethics; and the sector where the three intersect is where the three domains "educate" each other. As an activity, education is distinct from all three domains though informed by these domains and informing them. In the words of Arizmendiarrieta, "Teaching and learning are the first enterprise of a people (Pe, 216)." It is this sector that we will examine first, noting carefully the directive function of education.

Arizmendiarrieta's words on these domains. The block quotes that follow are from the Pensamientos but arranged as described in Chapter 3. The numbers are reference numbers for the quotes used by Azurmendi, not page numbers. The section headings are mine as well as the phrases in brackets that serve to complete the text for better reading. The Mediating Role of Education 
The best way for a community to become dynamic, to blossom in all kinds of initiatives, is to render available manifold options to all who are in the position to cultivate their higher faculties (208). Our good fortune of tomorrow depends more on the classrooms that we have gone through than the cribs in which we were born (212). The human being is human more through education than through birth (170). We should regard the lack of opportunities for education and training as the worse inheritance from the generation before us rather than the inequalities in economic standing (196). As much and only through education can human beings arrive at being human (171). People are not so much born as they are made through education (172). By virtue of an educational process, taken in its broadest meaning, by virtue of an accumulated knowledge and experience, we are made human beyond the fact that we are born human (173). People make themselves human through education. Civilization progresses at an increasing pace always through formative and educative action along the path of searching for human and social values (174). Human nature is not simply nature but rather more like artifacts, that is, nature transformed, adapted or developed by work and technology (175). The imperative of the present hour under all aspects of life and human relations is the opening and the projection of our minds. It imposes a radical change of mentality (192). Culture is the blood that always gives lineage and nobility to people (181). Education understood as the complex of ideas and thoughts that one adopts, is the key to the development and evolution of a people (190).

These insightful quotes re-state and complement what many other educators have said. From the moment of birth, the nurture of the human being is an educative process, the "leading out" and the coming Eorth, of a new member of the community. From the first words of the child to its first sentence, from the first scribbling to the first paragraph, the teaching-learning interaction is a continuous process. Formal schooling equips the human being with skills to live 
and work with others. The skills will eventually become part of a set of actions proper to a practice. Each praxis, as we have seen, has an immanent good which, in anticipation of the connectedness of life, is evaluated with other immanent goods, each nesting the other and directed toward the limit horizon called the good life. Whether the praxis is connected to others in what may be called the domain of politics or the domain of economics, it has been given an earlier orientation, thanks to the mediation of others in the interaction called education. In this interaction the complex of ideas and thoughts that one adopts is born. Education is experienced as first care to which we respond by returning the care in what may be called the fundamental basic moral experience. Part of this response is the pursuit of more education and putting this at the service of the community.

\section{Responsibility for One's Education}

Formation is much like the cultivation of all human excellence, among which stands out especially the capacity to think (226). The only valuable patrimony that does not tend to devalue itself is that of skills acquisition, that of training and formation (182). Many times we say that we ought to fight against social injustice, against the exploitation of the wage earner, against excessive accumulation of wealth, etc., etc.. but have we understood that the principal servitude, the first and most serious enslavement is the poverty of the intellect (195)? We should be concerned about the underdeveloped areas which are found almost anywhere, but especially those under our hats and berets...(192). Our heads are the underdeveloped regions that we must tend to even more (206). The 
ignorant person is more dangerous than the wicked person because the wicked person rests every now and then [from his wicked ways] but the ignorant never (205). In order to put the human potential under the best circumstances, one must apply the means of promotion as carefully as one carries out financial plans (225). Ideas and the mentality they promote are as indispensable for the progress of our cooperatives as the installations and machineries (227).

Equal Opportunities in and the Timeliness of Education

The enhancement of the talents of our people regardless of their economic condition-be it personal, be it that of the family-is the fundamental premise of all social action that is directed toward realizing a social order that is more human and more Christian (203). In a wild forest, the energy and vigor of the earth is equally spent on sap that renders a fruit tree fecund and bear delicious fruits as well as on sap that renders thorns and brambles to flourish (176). The excellence of the principle of [equal] opportunities in education ought to be compatible with the requirements of equitable distribution of the responsibilities that are indispensable to its realization [among various sectors of society] (222). - It is easier to educate a young person than to reform an adult (178). The most productive and profitable forecasting is the one we can use toward educating people upon whom wholesome [or humane] villages can be raised and set (207). Education is the key to the good fortune and future of our youth and of our very own society (209). Under no circumstances can we dream of a better tomorrow if we don't busy ourselves preparing for it, precisely by forming the tender souls of those who next will be the men and women of tomorrow (210). Children are our glory, or our ruin, whether they become one or the other depends on what our educational program would give them (211)

\section{Continuous and Continuing Education}

Teaching should be ongoing in order to be efficient (179). Plants take time to grow deep roots into the earth. We will say the same thing of sentiments and ideas taking time to grow to become the spirit of a society with one difference in that the latter takes more time than the former. For, while the life of plants is measured in decades or centuries, the story 
of peoples ordinarily is counted in thousands of years (213). The formation of persons begins a hundred years before their birth (214). Work and study ought to go hand in hand. One must never cease to pay attention to the potential of those who work nor underestimate the options to work whenever study gets bogged down or when one gets tired. The equality of opportunities ought to continue to have a bearing throughout life if, indeed, we want our communities to be adaptable (220).

\section{Education, Ethics, and Socio-Economics}

Education and cooperation are linked in the same way that work and the worker are, developing individually and collectively, overcoming the native and characteristic inertia in disposition and selfimportance (217). It has been said that the cooperative movement is an economic movement that uses the methods of education. The definition may also be modified to emphasize that the cooperative movement is an educational movement which uses the methods of economics (218). Let us marry WORK to CULTURE [through education], let us keep them tied together in the service of a progressive community, for the good of people (223). Cooperative enterprises must flee from inflexibility and return regularly to the training of its people, carefully considering their aptitudes, and to actualize them or adjust them systematically (224).

The socialization of culture [through education] has priority over the redistribution of wealth because the former enables us to think on the authentic humanization of work (204). Without education scarce goods and services cannot be produced nor distributed; education is the economy (177). The transformation and cultivation of man through education is inescapably assumed by every social theory (188). As a didactic and existential process, education has to include a dose of conscience and the habit of work (219). Education is the natural and indispensable point of support for the promotion of a new social order that is humane and just (191). Tools and machines need to be updated but above all there has a to be a change in mentality among those who are slated to run these tools and machineries (180). The most active agents of renewal are culture, science, and technology and these have a common denominator in a man with a new mentality (189). The young man who enters the world of work 
without a clear and positive (social) vision is a shipwreck in his spiritual life or a coward and traitor to the workers' movement (197).

Education, Politics, and Socio-economics

Knowledge is power and in order to democratize power, one must socialize knowledge beforehand. We accomplish nothing with the proclamation of rights, if afterwards the citizens whose rights we have proclaimed are incapable of administering those rights; if to be able to act, these citizens have no recourse but to count on a few indispensable people (193). One does not improve the lot of the masses without the masses. The emancipation of a class or of a people must begin with the empowerment of all sectors of society more or less on a massive scale (194). After the socialization of education inevitably comes the socialization of wealth and power; we may say that this is the indispensable and prior condition for the democratization and socio-economic progress of a people (186).

Democracy does not mix well with inherited privileges (221). We believe that more than lack of imagination we suffer the burden of vested interests and the inertia of an non-dependable culture [education]. The former renders the powerful and influential sclerotic and the latter keeps the masses lethargic. These are the real causes of our troubles and lack of potential (198). "Culture" as the privilege of one class is one of the major drawbacks of a community with regard to its progress; sometimes it implies anti-social and anti-economic-development [sentiments]. Those who recognize this fact without difficulty try to socialize culture at all costs. The socialization of culture, the access to it by the community without discrimination, the granting of opportunities for improvement to all to the extent of every person's potential, is a fundamental postulate of all social movement in our times. The proclamation of human rights that are made without a corresponding economic and cultural guarantee are ephemeral concessions for show and are not destined to produce the best results (199).

Education, Ethics, and Politics

Knowledge is power (184). Let us not forget that 
the bourgeoisie overcame and dethroned the aristocracy when they attained a superior education. Likewise the proletariat will be in a position to begin its social dominance when it is able to replace or relieve the bourgeoisie through its technical and cultural preparation and ability (187). Education is an indispensable element in the authentic emancipation of the worker (201). To change the constitution of a nation, to change the form or rule of a government, is something that can be done overnight. Likewise, to change the laws. To put something else ahead of others is relatively easy; it doesn't need much time. But no one will doubt that to change the beast in man, to perfect oneself a little, to control and overcome the bad inclinations that are born in all of us, is something that takes time and effort. It does not lend to improvisation (215).

We know the longing for liberty of the humble, of the proletariat, in a word, of the people. These longings are very good and speak very well in favor of the people (200). People who are conscious of their dignity, or who would not want to be at mercy of someone foreign and from the outside must promote before everything the cultivation and development of its own intelligence and will (202).

The narratives of the rearranged quotes clearly belongs to the genre of liberation narratives like those of Freire and the bishops' Economic Justice. They provide content for a reflection on the orienting function of education at the intersections of ethics, socio-economics, and politics. As I interpret the world of the text, I shall I bear in mind that when I narrate, I expand the field of action. I make claims and evaluate options. My value judgments are made using norms as well as objectives.

Interpretation at the intersection of ethics and socioeconomics. The world of the text that emerges is that of 
people who are educated for life through solidary work and who find meaning in ushering in a just and humane world. In this world, advances in technology are matched by increased intellectual capacity and a new mentality in people. Education creates human capital which increases productive capacity and hence goods and services that wouldn't be available without learning.

Now, this world emerges for me partly because of my hopes for such a world which hopes were and are nurtured by being engaged with people who share these hopes. These hopes have to be tempered by the reality that education has often been used to maintain an unequal social order where it has become the great sieve rather than the great equalizer. Where the educational aim of ushering in a humane and just social order is absent, education can create divisions and promote greed. Learning must lead to new insights into the common good and the desire to be responsible for it.

Interpretation at the intersection of politics and socio-economics. We note that Ricoeur describes the dissatisfaction of modern man in a society that defines itself in purely economic terms, therefore a society that bases itself on struggle and competition in which the individuals do not reap the fruits of their labor(TA, 326).

In contrast to this bleak assessment, the world that emerges from Arizmendiarrieta's educational aim orienting 
economics and politics is one where people are empowered to participate and thus overcome the vested interests of the privileged few. The optimism is tinged with realism in that education must do its proper role toward the true emancipation of the people in order to have true democracy. Cooperatives, ideally, provide the balance between the economically efficient and the just. The adverb 'ideally' must be emphasized because even at MCC the need to compete in a global market threaten to erode well-entrenched democratic practices. Tim Huet in an article in Dollars and Sense (December, 1997) reports that MCC workers are prompted to explore unionization in the face of increasingly aggressive management policies. He notes that Italian cooperatives have unions but MCC workers have in the past relied on the social councils to represent them and to protect their rights as workers and owners. The social councils, however, have no real power and are only in an advisory capacity vis-a-vis the governing councils.

Confronted by the forces of global economics, MCC managers need to reflect on their commitment to solidarity and workers may have to vote to give the social councils the powers of a union and make them de facto collective bargaining units with the right to call for a strike. On the other hand, by exercising the virtues of dialogue, they must avoid the adversarial relationship between union and 
management that has been partly blamed for the decline of the steel industry in the United States. The danger of a bloated union bureaucracy at MCC is obviated by the fact that service in the councils are not remunerated beyond what council members are paid on their regular jobs. The social council is an MCC invention and was designed by Arizmendiarrieta to increase, almost demand, participation from among the lowest ranks of workers. Where economics and politics collide as in MCC's drive to be competitive in the global market, the advice from the Pensamientos is the same: workers from all ranks must exercise their right to participate and be taken into account. Giving their social councils the power to call for a strike, even with the intent not to exercise it, is within the spirit of the Founder. Continuing education on how best to participate and a critical assessment of the current practice of preconference discussion groups to prepare members to vote on issues are a must if the democratic identity of MCC is to be kept.

\section{Interpretation at the intersection of ethics and} politics. Ricoeur notes that politics prolongs ethics by giving it the sphere in which to operate (TA, 234). The extension happens in the area of mutual recognition, in the requirement that makes me recognize your freedom as equal to mine. If the past is a good indicator of the future, the 
effort of projecting the ethical value of equality into the political arena is fraught with pitfalls. There will always be groups that will claim more equality than others, that is, groups segregating themselves by marking their distinctions and presuming these to be better than others. Education that promotes equality by enabling the masses to fully participate in shaping their common destiny will be a major factor in avoiding these pitfalls. The world that the text projects bases equality on quality education.

Responsibility in this regard includes engaging oneself in a continuous and continuing education; continuous because life is one connected whole and continuing because human knowledge forever advances. To be timely, education must be ongoing and it is in this sense that Arizmendiarrieta may be understood when he says that education begins a hundred years before anyone's birth. We are educating the unborn children of the next generation by the institutions we are creating today.

In Arizmendiarrieta's world of learning and doing, work is to be understood in the context of collaboration with God and, therefore, a privilege that must be made available to all. Thus MCC's drive toward the creation of sustainable jobs. Jobs creation, however, begins at school; a necessary condition to equal opportunity at the workplace is equal opportunity in the classrooms. 
The thrust toward globalization in MCC has given even greater emphasis on education in what is efficient and calculable, namely, the business and engineering sciences. At the same time some concerns are raised about what seems to be the abandoning of MCC values for the sake of being competitive. A director at the center for advanced studies in cooperative management acknowledged that such concerns have began to raise consciousness and appreciation for the ethical values that MCC stands for among the rank and file. What are these ethical values? The text suggests freedom, self-reliance, equality, and self-discipline. Implicit in the desire for liberty is a principle of the cooperatives that affirms the primacy of labor to capital to which MCC adheres.

Politics in the cooperatives may be designated as internal and external. Where a cooperative is part of a network, as in the case of MCC cooperatives, workers have to give attention to both internal and external politics in what is properly cooperative issues. Beyond this network, the cooperatives are part of a larger 'cooperation' that includes all other workers in the town, the nation, the world. At the intersection of ethics and politics, ethical values are given room to unfold. One of them is solidarity. Working in solidarity as an aspect of the good life. In examining the goodness of working in solidarity, the 
notions of standards of excellence, internal goods, life plans, evaluative appraisals, apply here as well as in Ricoeur's analysis of the good life. We recall that the fundamental basis of the aim for the good life is sought in praxis. We avoid solipsistic tendencies by observing that practices "are cooperative activities whose constitutive rules are established socially (OA, 176)." Prior to being specifically classed as cooperative work, working in solidarity is itself a praxis with internal goods immanent to it and whose constitutive rules are socially established in conjunction with other cooperatives.

The practice of working in solidarity consists in participatory work and ownership arrangements within a cooperative and/or within a network of cooperatives but competitive marketing of its products and services. The standards of excellence respecting participatory working arrangements refer to an immanent good that is evaluated through worker interest and satisfaction. This evaluation includes but is not limited to deliberations of means toward the attainment of ends in a cooperative. This evaluation is also indicative of a shared life plan that gives a broad unity to actions found in a cooperative practice. A shared life plan may not always be articulated and may include faroff ideals thus making deliberation in a cooperative oscillate between far-off ideals that are made precise as 
the occasion arises, and the weighing of advantages and disadvantages of the choice for this life-plan on the level of practice.

An example may illustrate an instance where this kind of deliberation is needed. Theoretically, a cooperative could enter into partnership with an owner of a sweat shop who pays below minimum wages and violates child labor laws by providing raw materials and marketing the finished product at a handsome profit. The ideal cooperators not only deliberate on the quality of fabrics they produce for the consuming public and how reliable is the sweat shop operator in delivering finished goods, but also whether the life-plan they share can unfold in these circumstances.

A teleology proper to cooperatives. Cooperative ethics may be understood as an ethics of the praxis proper to member-owners of cooperative enterprises. Indeed, the engineers in a tool-making factory are evaluated on a regular basis according to the objectives that are part of the description of their jobs. The "good" in this instance toward which they tend is the perfection of their trade. Their ability to evaluate, however, extends beyond the confines of their trade so that at the same moment that they are evaluating how well they have done on the job, they are also evaluating whether they are still interested in their jobs, satisfied with their working environment, or happy 
with life itself. There is a connectedness in the ends of their various activities. This connectedness is the basis of a teleology that both gives value to what is proper to their positions and at the same time connects all ends, thus defining for them what is ethical conduct.

With minor adaptations, I found in the ethical aim of Ricoeur and the educational aim of Arizmendiarrieta a shared teleology. Both tend toward the common good which I define as living and working together in the spirit of solidarity for the creation and maintenance of just institutions. Solidarity implies a union of interests, of mutual support, but also a commitment to the common good.

As was stated earlier, the educational aim of Arizmendiarrieta is the informed engagement of people in settings where they can work in solidarity to usher in a humane and just social order. Historically, the setting has evolved to its present network of cooperative enterprises with their requirements of voluntary membership, democratic organization, primacy of labor, participatory management, distributive solidarity, social transformation, and education, among others. Obviously, positions must be made available to people with the needed skills and so one measure that MCC uses to gauge how well it has done in a given year is to count the number of new jobs the member cooperatives have created. The emphasis is on the creation 
of quality jobs which invariably requires intensive as well as extensive training in a university.

Two perspectives arise from a Ricoeurian reading of Arizmendiarrieta. The first gives the vision of a community as mediator of the dignity of a person in the context of the bonds that the person fosters with the community. The central role of education in this mediation, therefore, of the university, is highlighted and pointed toward the direction of active participation in creating just institutions. The second adds color to human work in that it can be seen as both an act of interpreting Iife, a movement toward self-understanding, and, once the work is completed, it becomes a means to arrive at new interpretations of life. These perspectives interwoven into stories that are in turn grafted into the longer stories of mankind may provide the narratives of ourselves, individually and as a community and the basis for expressing cooperative ethics.

\section{The Example of the University of Mondragon and Its Cooperatives}

In October, 1997, a new version of the multi-media presentation that introduces visitors to the Mondragon Cooperative Corporation (MCC) highlights the merger of several colleges in the province of Guipuzcoa, Spain, into the University of Mondragon. These colleges were inspired 
by the teaching and work of Arizmendiarrieta, assistant pastor of the parish of Mondragon who opened the first of these schools in 1943. Today, that first school is a Eullfledged engineering college and is credited by many as the incubator of a network of some 115 cooperatives that today is one of Spain's most dynamic group in manufacturing, banking, and marketing. The other colleges include those of business, foreign languages, teacher education, and a center for graduate studies in cooperative management.

What is unique about the University of Mondragon is its being an integral part of MCC, an entrepreneurial organization that prides itself in the number of quality jobs it creates each year. In 1996, MCC topped 30,000 members and is adding an average of 800 or more jobs each year, which jobs are virtually guaranteed for life. In the 41 years of its existence, MCC has not laid off any workermember though it may retrain some for needed new skills. For purposes of training and retraining the school is what Arizmendiarrieta called "the first enterprise of a people" and within two years of his arrival in Mondragon he opened one. In that polytechnic school, he taught a mix of religion and sociology for 13 years before the first worker cooperative emerged in 1956. Three years after the first cooperative, he initiated a bank over the opposition of his collaborators. Today, it is one of spain's ten largest 
banks. In 1974, two years before he died, Arizmendiarrieta surprised his associates with a proposal for creating an industrial research center. Today, this center subcontracts for NASA and the European Space Agency as well as for the industrial cooperatives.

Political realism. Each cooperative in the network follows the same structure of governance designed to maximize participation at all levels. Three groups in varying proportions make up the general assembly of the school: 50\% consists of all the worker-members (faculty and staff), $25 \%$ represents the interests of collaborating organizations, and $25 \%$ represents the recipients of the services of the university. Ultimate power is vested on the general assembly which meets once a year. Every two years the general assembly elects 12 representatives into the governing council and 3 into an internal audit committee. Members of the governing council serve their four-year term without additional pay beyond what their regular jobs paid them. They interview and place applicants to positions of management, the director among them. The director of the university sits in the meetings of the governing council and makes recommendations but has no vote. MCC makes a distinction between governance and execution. Responsible to the director are department heads and together they form the management council and are tasked to 
manage operations but not to hire or fire. Employee benefits are the concern of the social council, a body whose members are elected from the departments where they worked and acts on an advisory capacity to the governing council. Economic realism. The spirit of solidarity inspired the founders to keep their salaries within the ratio of $1: 3$ but in 1987 this was revised to $1: 6$ in recognition of the added responsibilities imposed upon top management. Since few are paid on the first level, the actual average ratio between the lowest and highest paid is closer to 1:4.5. The bank has recently adopted a ratio of $1: 9$ but its top managers are still earning less than the managers of banks comparable in size while its least paid workers are earning slightly more than their counterparts. Salaries of all positions are posted and this information is available to all members of the cooperative.

Financially, the school is supported by tuition paid by students who can afford it. Those who cannot, may apply for a work-study program offered by Alecop, the student cooperative, where hands-on learning occurs in running a cooperative enterprise. They may also apply for scholarships offered by government agencies and the cooperatives whose bylaws require that $10 \%$ of their earnings be given back to the community. The school is a community effort in every sense. The democratic organization of the 
school is enhanced by structures that encourage, almost demand, participation from all sectors. By gathering into the general assembly faculty and staff, benefactors and school equipment suppliers, and students and parents, the conversation is broadened to include all stakeholders.

Educational realism: teaching the cooperative way of 1ife. When pressed for an answer to the question, "Who teaches the cooperative style of work and living at MCC?," an instructor at the engineering school in 1996 said something to the effect that no one does in particular, but everyone in general. After some 2,000 study circles that Don Jose Maria formed with the youth of Mondragon (MM, 32) while he was still alive, some 30,000 worker-members now teach each other the values of cooperative work and living in their small discussion groups at factory sites, as well as in classrooms. They do so mostly through their lives, lives that were rendered productive and meaningful by a cooperative ethic. Those of us who got to know some of them came back with a distinct impression of lives well-lived.

But MCC engages in formal cooperative education as well. In addition to Alecop, the student cooperative cited earlier, the University of Mondragon has a center designated to assist would-be entrepreneurs toward the realization of their ideas and the formation of new enterprises, cooperatives or otherwise. Dubbed Saiolan, the center was 
created in 1985 in collaboration with the Basque Government with the mission of contributing to the development of enterprises through information, training, research, and assistance in the creation of new ventures. In 1990-91, it engaged 24 scholarship recipients who elaborated six sectoral studies, nine feasibility studies, and initiated four new ventures. There were 13 projects in 1997, five of which culminated in the creation of five new firms. The rest of the projects are in different phases of feasibility studies and prototyping. The firms can expect assistance from Saiolan throughout the life cycle of a new enterprise, from its creation to its consolidation. The firms may or may not organize themselves as cooperatives and, if cooperatives, they may or may not apply for affiliation with MCC .

For graduate studies in cooperative management, MCC has the center called otalora. The center conducts short courses for MCC managers as well as foreign students. This was the site of the conferences and workshops given to the study groups from the University of San Diego in the summers of 1996 and 1997.

In summary, the University of Mondragon is one more step toward the consolidation of the educational movement that Arizmendiarrieta initiated, an educational movement that uses economic activities as part of the learning cycle 
and which considers the places of work as extensions of the classroom in the lifelong effort at educating a people of different talents and interests into a community marked by care for one another and confident hope for the future. The educational movement is guided by a social vision that is first informed by the social teachings of the Catholic Church and then adapted to the realities of the difficult task of lifting up the masses by the energy and creativity of the masses. The movement is far from having accomplished its goals but it has accumulated valuable experience, considerable expertise and wealth. It has done so without compromising the value of working and living in solidarity. Fidelity to this value is owed in large measure to the example of Arizmendiarrieta who repeatedly refused to trade his bicycle for a car his collaborators insisted he used for the sake of his heart. The bicycle then was the mode of transportation of most workers and Arizmendiarrieta wanted to be one of them. Another expression of this solidarity is his detachment from wealth. The bank he created accrued assets to the millions of dollars when he died in 1976 but not a penny of it went to him or his relatives. He was quite content with the stipend the parish of Mondragon paid its assistant pastor. He lived what he preached: "To create but not to dominate; to render productive but not to possess." 


\section{Implications for Community Development}

How to emulate the parish school turned University of Mondragon and its cooperatives given our particular circumstance is the challenge that inspired this study. Situated next to the Mexican border, we live in a very diverse environment, culturally and economically. on both sides of the border, people share the hope that someday this border will be just like the Canadian border, open and unguarded. One small step toward this reality is the creation of cooperatives on both sides of the border stimulated and coordinated by the cooperation among universities on both sides of the border. One principal means of that stimulation is a curricular offering on cooperatives, of which cooperative ethics could be a core subject.

Community development can take either of two routes: one that is characterized by a singular focus on economic development to the neglect and detriment of the social bonds created by a common history that makes people into a community and communities into a nation, and another that is characterized by an integration of the socio-economic, political, and ethical aspects of community living. To promote the second route I suggest that the university is the institution of choice to initiate, coordinate, and maintain this latter kind of development. The success of 
the educational enterprise that propels and sustains MCC, suggests that this integral approach is not only possible but highly desirable.

Recommendations: Toward a Cooperative Catholic Oniversity

Recommendations derived from this study were recently put forward, as part of an effort by a not-for-profit group doing education consultancy, to reopen a Catholic university that closed three years ago and has remained closed.

Democratic structure. In broad outlines, the proposal suggested inclusion of all stakeholders in a general assembly which shall be charged to elect a board of governors and an audit committee. The department chairs and other administrative personnel shall constitute the management council and the teachers' union shall constitute the social council. Both councils shall be in an advisory capacity vis-a-vis the board of governors upon which governing authority shall be vested. The board of governors shall appoint the president of the university. The president shall sit in the deliberations of the board but shall have no vote.

Ethical orientation. The curricular offerings envisioned shall include interdisciplinary, humanities-based leadership studies designed to acquaint and equip students with a method of interpretation pioneered by Paul Ricoeur. Catholic teaching on social justice as well as pastoral 
letters of local bishops shall be studied by teams critically but with implementation in mind. Evaluation methods and instruments shall be devised to appraise the justice commitment of the school and of other Catholic institutions.

Religion studies shall be oriented toward defining and refining a way of life, not solely to meet course requirements. The gap between the "ivory tower" reputation of academia and the practical needs of the city shall be closed through service-oriented study and dialogue.

Entrepreneurial orientation. One percent of collectable tuition shall be dedicated toward feasibility studies of the creation of new enterprises, coordinating and maintaining an alliance among these enterprises, and making curricular offerings needed to prepare students to carry on these tasks. This shall lead to the creation of a Saiolantype of business incubator within the university. Team formation shall be emphasized throughout the studies and skills of dialogue shall be developed in joint research projects intended to discover how teams may be formed in schools, equipped with the needed skills, and then employed by companies and government agencies as teams through contract work that meet the requirements of dependability. Specific areas of the world of work, particularly, peace and order, the environment, the media, education, health 
services, infrastructure development, shall be studied by interdisciplinary teams with the intention of entering them as teams. The teams in due time shall be organized as cooperatives and linked to one another in a network that shall be coordinated initially by the school but eventually by themselves.

Christian community orientation. The university's Campus Ministry shall promote collaboration among parishes on social issues that are common to all and arrange for community service learning that is parish oriented. It shall pioneer among students new liturgical expressions and orient them to Catholic organizations such as student Catholic Action, CFC Youth for Christ, Teens Encountering Christ, Marriage Encounter among its graduate students, and other organizations that give community support to Christian living. It shall solicit from parishes scholarship funds to support students orienting their studies toward parish ministry with the objective of equipping the laity for parish administration, catechetical instruction, and participation in missionary work. It shall have an employment referral service to serve its student body as well as the unemployed in its network of parishes. This referral service shall keep tab of expansion plans by local businesses, identify the manpower and skills they will need, and promote alliances between them and the school through 
internship programs.

Coordination with Catholic secondary schools. With the valuable lessons from MCC schools in mind, social awareness, initiative, and imagination shall be encouraged at a tender age through student organizations. The university shall forge alliances with secondary schools to improve student achievement as well as create occasions in which students exercise initiative and imagination. 


\section{CHAPTER 5}

\section{CONCLUSIONS}

The definition of cooperative ethics brought together the philosophical reflections of Ricoeur on the ethical aim and the thoughts of Arizmendiarrieta on the educational aim. I can cite three accomplishments of this effort. The first is that cooperators now have another place to start from with their reflections on the ethical aim proper to their praxis. Throughout this study, the assumption has been that the connectedness of life is evident to everyone and that cooperators see themselves not just as cogs in the production wheel but as persons whose valuations create new standards of excellence not only on the quality of their products but also on the quality of their lives.

The cooperators' reflections on the quality of their lives could lead them to the question, "Who am I?" The hermeneutical phenomenology of Ricoeur on the narrative self in Chapter 3 provides a language that could facilitate their reflections. Observing that over the years they have become different and yet somehow stayed the same, they can appreciate the stories about themselves that enable them to mediate the two poles of being the same and being another. These stories are deeply embedded in their culture which is 
the well-spring of the words they use to tell their scories. This awareness could allow them to assimilate new words, therefore, new realities, without alienating themselves from their history. As new words are coined and become part of their vocabulary, they align these according to the trajectory of their stories. This is their permanence in time even as time passes.

Ricoeur symbolizes this permanence in time by using the phenomenon of character and the ethical notion of selfconstancy, the two poles of the dialectics of personal identity and thus the two modalities of their permanence in time. Character is the perpetuation of the same, that by which they can be identified and reidentified; selfconstancy is that manner of conducting themselves so that others can count on them as persons. Between these two notions lies narrative identity which renders each cooperator unique and irreducible to the collective although in close relationships with others. For it is in response to the other in need that this permanence symbolized by character and self-constancy attains its fullest meaning. The second accomplishment is that the definition encapsulates the liberation narratives in Arizmendiarrieta, Freire, and Catholic social teaching reviewed in Chapter 2 . It modifies the notion of "function as such" for man into the function as such for cooperators. Beginning from the 
valuation of their productivity at work, continuing on to the valuation of the worthwhileness of their lives, the definition suggests that cooperators can find in the "nesting of ends" a connectedness that adds significance to the transactions that maintain their just institutions and lead to the creation of new ones. Their personal unfolding from incapacity to capacity through the mediation of the other in "good dialogue" and the movement of their cooperatives from a community with limited options to a community of infinite possibilities through the mediation of their educational system is a story of liberation that points to and renders credible a larger story of liberation that is propelled by hope and a passion for the possible. Thirdly, the definition recognizes and maintains an educational aim as the basis for its expressed hope and, therefore, orientation, for a just and humane society. As was noted in Chapter 4, this hope has to be tempered by the reality that education has often been used to maintain an unequal social order where it has become the great sieve rather than the great equalizer. Where the educational aim of ushering in a humane and just social order is absent, education can create divisions and promote greed. This reservation finds parallel in Ricoeur's observation of the ambivalence of distributive justice taken apart from the ethical aim. 
Overall, this study demonstrates that the ideal cooperative is or could be an agent of change and should be guided by an ethics that properly may be called cooperative ethics which now may also be seen as an ethics of change through education and work, the principal conduits of change. It adds depth to the understanding and day-to-day living of the principles declared by the International Cooperative Association by its analysis of the insights of Ricoeur on ethics, his related elaborations on action and change, and of the thoughts of Arizmendiarrieta on education that considers it as an activity that ushers in change. The phenomenology of change and of human action demonstrates that intervention consists of the union of two components: the intentional and the systemic. Because change implies movement, and therefore, direction, I argued that work as a conduit of change, and, by extension, the economic activity of the cooperatives, is never ethically neutral. The choice, therefore, is not between an ethical decision and a business decision when the cooperatives deliberate. Rather, it is a question of which ethical decision is an extension of the cooperative as a historical community projecting itself into the future.

Reflecting on the Pensamientos in the format demonstrated in this study can help cooperators, whether MCC members or not, deepen their ethical commitment to their 
cooperatives and their communities. Symbols of cooperation bring many meanings and the newness of everyday transactions suggest new possibilities. Cooperators are given Eresh challenges everytime to interpret the "world of the text" and now they have another method. 
APPENDIX A

INTERSECTION OF DOMAINS
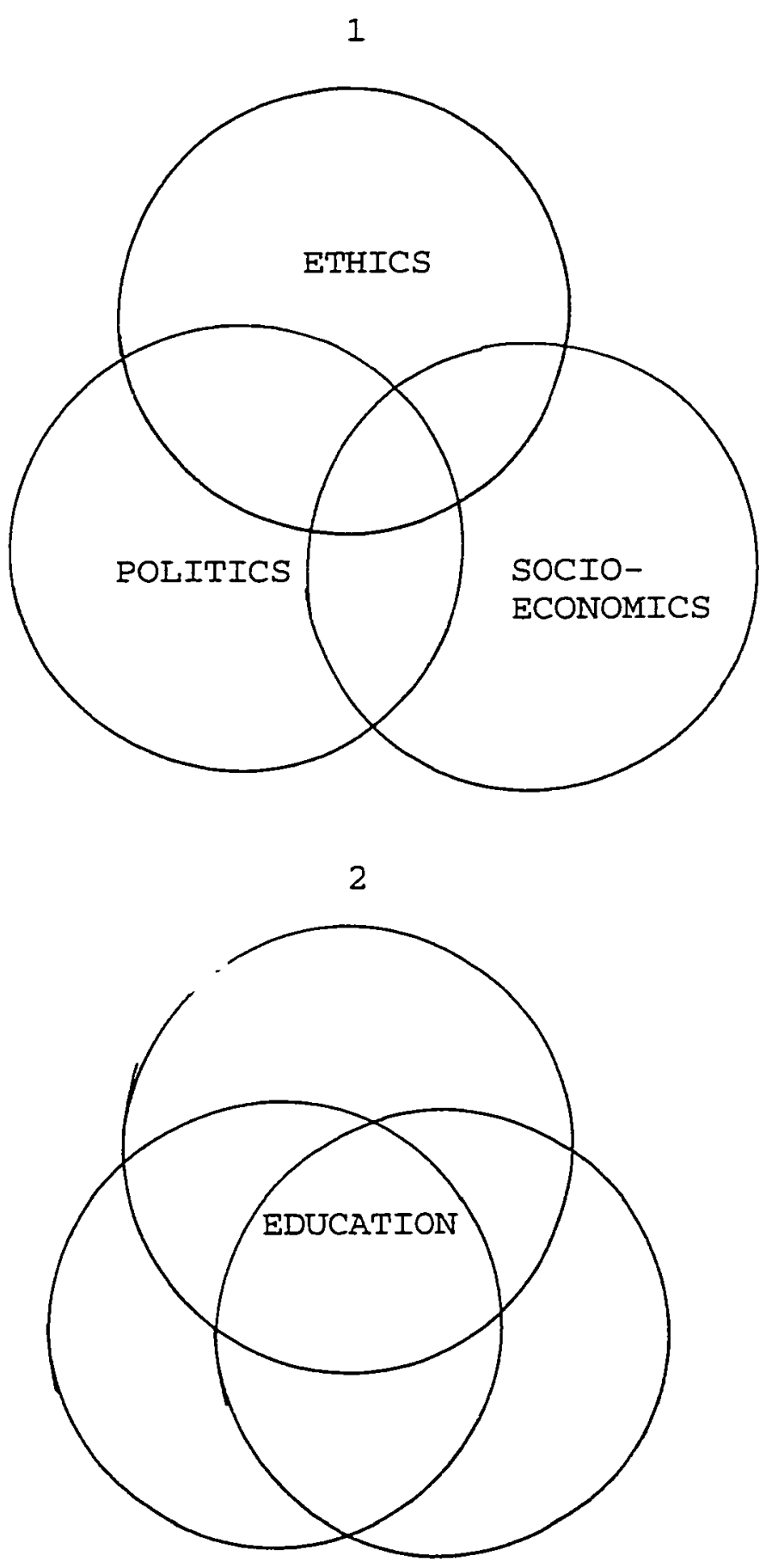


\begin{abstract}
APPENDIX B
PRINCIPLES OF THE

INTERNATIONAL CO-OPERATIVE ALLIANCE

(Source: Website of NASCO)

STATEMENT ON THE CO-OPERATIVE IDENTITY

Adopted in Manchester (UK) - 23 september 1995

The statement on Co-operative Identity was adopted at the 1995 General Assembly of the International Co-operative Alliance (ICA), held in Manchester on the occasion of the Alliance's Centenary. The statement was the product of a lengthy process of consultation involving thousands of co-operatives around the world.
\end{abstract}

DEFINITION

A co-operative is an autonomous association of persons united voluntarily to meet their common economic, social, and cultural needs and aspirations through a jointly-owned and democratically- controlled enterprise.

\title{
VALUES
}

Co-operatives are based on the values of self-help, selfresponsibility, democracy, equality, equity, and solidarity. In the tradition of their founders, co-operative members believe in the ethical values of honesty, openness, social responsibility, and caring for others.

\section{PRINCIPLES}

The co-operative principles are guidelines by which cooperatives put their values into practice.

1st PRINCIPLE: VOLUNTARY AND OPEN MEMBERSHIP

Co-operatives are voluntary organizations, open to all persons able to use their services and willing to accept the responsibilities of membership, without gender, social, racial, political, or religious discrimination.

2nd PRINCIPLE: DEMOCRATIC MEMBER CONTROL

Co-operatives are democratic organizations controlled by 
their members, who actively participate in setting their policies and

making decisions. Men and women serving as elected representatives are accountable to the membership. In primary co-operatives members have equal voting rights (one member, one votel and co-operatives at other levels are organized in a democratic manner.

$3 r d$ PRINCIPLE: MEMBER ECONOMIC PARTICIPATION

Members contribute equitably to, and democratically control, the capital of their co-operative. At least part of that capital is usually the common property of the co-operative. They usually receive limited compensation, if any, on capital subscribed as a condition of membership. Members allocate surpluses for any or all of the following purposes: developing the co-operative, possibly by setting up reserves, part of which at least would be indivisible; benefitting members in proportion to their transactions with the co-operative; and supporting other activities approved by the membership.

\section{4th PRINCIPLE: AUTONOMY AND INDEPENDENCE}

Co-operatives are autonomous, self-help organizations controlled by their members. If they enter into agreements with other organizations, including governments, or raise capital from external sources, they do so on terms that ensure democratic control by their members and maintain their co-operative autonomy.

5th PRINCIPLE: EDUCATION, TRAINING AND INFORMATION

Co-operatives provide education and training for their members, elected representatives, managers, and employees so they can contribute effectively to the development of their co-operatives. They inform the general public -particularly young people and opinion leaders -- about the nature and benefits of co-operation.

6th PRINCIPLE: CO-OPERATION AMONG CO-OPERATIVES

Co-operatives serve their members most effectively and strengthen the co-operative movement by working together through local, national, regional, and international structures.

7 th PRINCIPLE: CONCERN FOR COMMUNITY 
While focusing on member needs, co-operatives work for the sustainable development of their communities through policies accepted by their members. 


\section{APPENDLX C}

\section{TOP 100 U.S. COOPERATIVES}

(Source: Website of CoopI00)

Dollars in millions

\begin{tabular}{|c|c|c|c|c|c|c|c|c|}
\hline \multicolumn{2}{|c|}{ RANK } & COOPER & \multicolumn{3}{|c|}{ REVENUE } & \multicolumn{2}{|c|}{ ASSETS } & \multirow{2}{*}{$\begin{array}{c}\text { TNDUS } \\
\text { TRY }\end{array}$} \\
\hline '96 & $' 95$ & ATIVE & 1996 & 1995 & 1991 & 1996 & 1995 & \\
\hline 1 & 1 & $\begin{array}{l}\text { Farmland } \\
\text { Industries }\end{array}$ & 9,789 & 7,257 & 3,638 & 2,586 & 2,186 & $\begin{array}{l}\text { Agricultu } \\
\text { re }\end{array}$ \\
\hline 2 & 2 & $\begin{array}{l}\text { Harvest } \\
\text { States } \\
\text { Cooperative }\end{array}$ & 8,154 & 5,057 & 3,033 & 1,229 & 925 & $\begin{array}{l}\text { Agricultu } \\
\text { re }\end{array}$ \\
\hline 3 & 3 & $\begin{array}{l}\text { Wakefern } \\
\text { Food Corp. }\end{array}$ & 4,304 & 4,063 & 3,534 & 667 & 627 & $\begin{array}{l}\text { Supermar } \\
\text { ket }\end{array}$ \\
\hline 4 & 5 & $\begin{array}{l}\text { Mid America } \\
\text { Dairymen Inc. } \\
\text { (1) }\end{array}$ & 4,085 & 3,681 & 2,748 & 850 & 773 & $\begin{array}{l}\text { Agricultu } \\
\text { re }\end{array}$ \\
\hline 5 & 4 & $\begin{array}{l}\text { TOPCO } \\
\text { Associates } \\
\text { Inc. }\end{array}$ & 3900 & 3700 & & 2140 & 214 & $\begin{array}{l}\text { Supermar } \\
\text { ket }\end{array}$ \\
\hline 6 & 6 & $\begin{array}{l}\text { Land O'Lakes } \\
\text { Inc. }\end{array}$ & 3,486 & 3,014 & 2,458 & 1,235 & 1,149 & $\begin{array}{l}\text { Agricultu } \\
\text { re }\end{array}$ \\
\hline 7 & 7 & $\begin{array}{l}\text { Associated } \\
\text { Wholesale } \\
\text { Grocers }\end{array}$ & 3,096 & 2,975 & 2,459 & 461 & 454 & $\begin{array}{l}\text { Supermar } \\
\text { ket }\end{array}$ \\
\hline 8 & 15 & $\begin{array}{l}\text { Ag Processing } \\
\text { Inc. }\end{array}$ & 2,765 & 2,150 & 864 & 746 & 700 & $\begin{array}{l}\text { Agricultu } \\
\text { re }\end{array}$ \\
\hline 9 & 12 & $\begin{array}{l}\text { ACE } \\
\text { Hardware } \\
\text { Corp. }\end{array}$ & 2,742 & 2,436 & 1,704 & 916 & 759 & $\begin{array}{l}\text { Hardwar } \\
\text { e \& } \\
\text { Lumber }\end{array}$ \\
\hline
\end{tabular}




\begin{tabular}{|c|c|c|c|c|c|c|c|c|}
\hline 10 & 13 & Cenex & 2,683 & 2,244 & 1,686 & 1,459 & 1,264 & $\begin{array}{l}\text { Agricultu } \\
\text { re }\end{array}$ \\
\hline 11 & 10 & Roundy's Inc. & 2,579 & 2,488 & 2,539 & 435 & 407 & $\begin{array}{l}\text { Supermar } \\
\text { ket }\end{array}$ \\
\hline 12 & 11 & $\begin{array}{l}\text { Spartan } \\
\text { Stores }\end{array}$ & 2,521 & 2,495 & 2,024 & 387 & 386 & $\begin{array}{l}\text { Supermar } \\
\text { ket }\end{array}$ \\
\hline 13 & 14 & $\begin{array}{l}\text { Countrymark } \\
\text { Cooperative } \\
\text { Inc. }\end{array}$ & 2,486 & 2,237 & 2,144 & 609 & 588 & $\begin{array}{l}\text { Agricultu } \\
\text { re }\end{array}$ \\
\hline 14 & 11 & $\begin{array}{l}\text { Cotter \& Co. } \\
\text { (True Value) }\end{array}$ & 2,442 & 2,437 & 2,140 & 854 & 820 & $\begin{array}{l}\text { Hardwar } \\
\text { e \& } \\
\text { Lumber }\end{array}$ \\
\hline 15 & 8 & $\begin{array}{l}\text { Associated } \\
\text { Milk } \\
\text { Producers } \\
\text { Inc. }\end{array}$ & 2,154 & 2,502 & 2,720 & 439 & 464 & $\begin{array}{l}\text { Agricultu } \\
\text { re }\end{array}$ \\
\hline 16 & 19 & Gold Kist Inc. & 1,956 & 1,689 & 1,259 & 976 & 822 & $\begin{array}{l}\text { Agricultu } \\
\text { re }\end{array}$ \\
\hline 17 & 17 & $\begin{array}{l}\text { Certified } \\
\text { Grocers of } \\
\text { California } \\
\text { Ltd. }\end{array}$ & 1,949 & 1,823 & 2,768 & 373 & 399 & $\begin{array}{l}\text { Supermar } \\
\text { ket }\end{array}$ \\
\hline 18 & 18 & $\begin{array}{l}\text { ServiStar } \\
\text { Corporation }\end{array}$ & 1,730 & 1,802 & 1,525 & 468 & 467 & $\begin{array}{l}\text { Hardwar } \\
\text { e \& } \\
\text { Lumber }\end{array}$ \\
\hline 19 & 16 & Agway, Inc. & 1,663 & 1,592 & 3,490 & 1,244 & 1,225 & $\begin{array}{l}\text { Agricultu } \\
\text { re }\end{array}$ \\
\hline & & $\begin{array}{l}\text { Lumbermen's } \\
\text { Merchandisin }\end{array}$ & & & & & & $\begin{array}{l}\text { Hardwar } \\
\text { e \& }\end{array}$ \\
\hline 20 & 21 & g Corp. & 1,662 & 1,471 & & $97 p$ & 97 & Lumber \\
\hline 21 & 26 & $\begin{array}{l}\text { Shurfine } \\
\text { International, } \\
\text { Inc. }\end{array}$ & 1,555 & 1,171 & & 59 & 62 & $\begin{array}{l}\text { Supermar } \\
\text { ket }\end{array}$ \\
\hline & & $\begin{array}{l}\text { Hardware } \\
\text { Wholesalers }\end{array}$ & & & & & & $\begin{array}{l}\text { Hardwar } \\
\text { e \& }\end{array}$ \\
\hline 22 & 20 & Inc. & 1,548 & 1,635 & 1,141 & 424 & 416 & Lumber \\
\hline
\end{tabular}


$\mathrm{CF}$ Industries

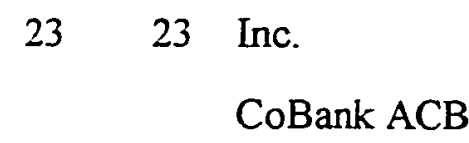

$24 \quad 22 \quad(2)$

CoBank ACB

$25 \quad 24$ Agribank

$1,468 \quad 1,383$

803

$\begin{array}{lll} & & \text { Agricultu } \\ 1,445 \quad 1,477 & \text { re }\end{array}$

$1,441 \quad 1,384 \quad 1,144$ $20,04 \quad 20,39$

$9 \quad 9$ Finance 26

$26 \quad 25$

Ocean Spray

$1,400 \quad 1,328$

743

$18,64 \quad 16,52$

Foremost

$1,439 \quad 1,368 \quad 1,380$

93 Finance

Agricultu
Farms USA
$27 \quad 42$ Cooperative
Growmark,
2829 Inc.
United
$29 \quad 35$ Grocers
Healthpartner
3030 s Inc. (3)
Group Health
Cooperative of Puget
3133 Sound

1,357

822

743

$1,350 \quad 1,122$

846

353

354 re

$1,302 \quad 1,01$

859

384

$\begin{array}{llllll}1.178 & 1,111 & 451 & 638 & 646 & \text { Health }\end{array}$

$1,144 \quad 1,039$

663

627

653 Health

Southern

States

3236 Cooperative

$1,123 \quad 1,014$

945

386

Agricultu

Oglethorpe

Power

3327 Corporation

1,10

1,150

1,083

5,362

5,438 Utility

Associated

3431 Grocers Inc.

1,090

1,055

1,119

246

Supermar

U.S. Central

3534 Credit Union

$1,056 \quad 1,029 \quad 1,812$

$17,92 \quad 19,30$

Twin County

3628 Grocers

1.032

1,149

1,201

136

Sunkist

3732 Growers, Inc.

$973 \quad 1,054$

920

182

5

5 Finance

Supermar

154 ket

Agricultu

194 re 
Associated

\section{Food Stores \\ Darigold \\ 3938 Farms}

AgFirst Farm

Credit Bank

$40 \quad 39 \quad(4)$

Tri-Valley

4140 Growers

Prairie Farms

4243 Dairy Inc.

California

Milk

4344 Producers

Plains Cotton

Co-op

44

37 Association

National

Cooperative

Refinery

Association

4645 Inc.

Pro-Fac

Cooperative

46

Inc

Riceland

4746 Foods, Inc.

Basin Electric

Power

48

81 Cooperative

Navy Federal

49

52 Credit Union

Associated

Wholesalers

5053 Inc. $\begin{array}{llllll}937 & 842 & 746 & 197 & 182 & \text { ket }\end{array}$

$931906 \quad 719 \quad 266 \quad 260$ re

$\begin{array}{lll}898 & 894 & 881\end{array}$

$10,54 \quad 10,35$

Agricultu

re

875

$853 \quad 800$

284265 re

Agricultu

Agricultu

$763 \quad 721 \quad 745$ re

re

Agricultu

$121 \quad 110$ re

$811 \quad 754$

Agricultu

$785 \quad 1,014$

719

191

175 re

760

596

847

429

Agricultu

re

Agricultu

$739 \quad 522$

644690 re

Agricultu

$734 \quad 737$

641

325

300 re

re

$729 \quad 400$

43

2,448

2,497 Utility

709

664

48

$8,922 \quad 8,723$ Finance

Supermar

$\begin{array}{lll}702 & 647 & 393\end{array}$

93

85 ket 
Certified

Grocers

5148 Midwest

698

Milk

Marketing

5254 Inc. (5)

69

American

Crystal Sugar

5356 Co.

$688 \quad 606$

465

Agricultu

Michigan

Livestock

54

47 Exchange

683

721

111

Agricultu

Sun-Diamond

Growers of

California,

55

Inc.

$678 \quad 672$

61

Agricultu

MFA

$56 \quad 60$ Incorporated

$667 \quad 593$

465

288

59 re

Dairyman's

Co-op

Creamery

$57 \quad 59 \quad$ Association

$661 \quad 592$

142

Agricultu

AgAmerica

$58 \quad 55$ FCB

655

636

$657 \quad 7,763$

7,462

Agricultu

270 re

North

Carolina

Electric

Membership

5949 Corp.

650

711

645

1,543

1,637 Utility

Agricultu

6045 Calcot Ltd.

$642 \quad 739$

627

192

171 re

Staple Cotton

Cooperative

Association,

6151 Inc

$640 \quad 664$

71

Agricultu

Atlantic Dairy

$62 \quad 57$ Cooperative

$619 \quad 602 \quad 451$

87

87 re

Agricultu 
Affiliated

$$
63
$$

$$
61 \text { Foods }
$$

Dairylea

Cooperative

6466 Inc.

SF Services,

6562 Inc.

Food Service

Purchasing

$66 \quad 63$ Cooperative

67

Wescorp FCU

Associated

Electric

6869 Cooperative

Seminole

Electric

6964 Cooperative

National

Grape Co-op

Association

7065 (Welch's)

Affiliated

Foods

7167 Cooperative

72

Key Foods

CFC

$73 \quad 75$ (NRUCFC

Blue Diamond

$74 \quad 77$ Growers

$75 \quad 72$ URM Stores
$608 \quad 570$

594

487

$592 \quad 539$

451

85

77 ket

Agricultu

285

66

54 re

192200 re

Agricultu

$$
\text { re }
$$

$\begin{array}{lll}580 & 537 & 401\end{array}$

49

43 Franchise

11,93

$575 \quad 674$

9,672

2 Finance

$\begin{array}{llllll}554 & 535 & 451 & 803 & 837 & \text { Utility }\end{array}$

$\begin{array}{llllll}557 & 464 & 412 & 1,378 & 1,428 & \text { Utility }\end{array}$

$554 \quad 535 \quad 45$

451

803

\author{
837 Utility
}

$\begin{array}{llllll}551 & 509 & 419 & 313 & 306 & \text { re }\end{array}$

520

$\begin{array}{llll}417 & 73 & 69 & \begin{array}{l}\text { Supermar } \\ \text { ket } \\ \text { Supermar }\end{array} \\ 653 & 62 & 69 & \begin{array}{l}\text { ket }\end{array}\end{array}$

$514 \quad 541 \quad 653$

$505 \quad 440 \quad 429$

8,054

7,081 Finance

502

422

424

187

Agricultu

238 re

Supermar

493

462

431

123

120 ket 
Recreational

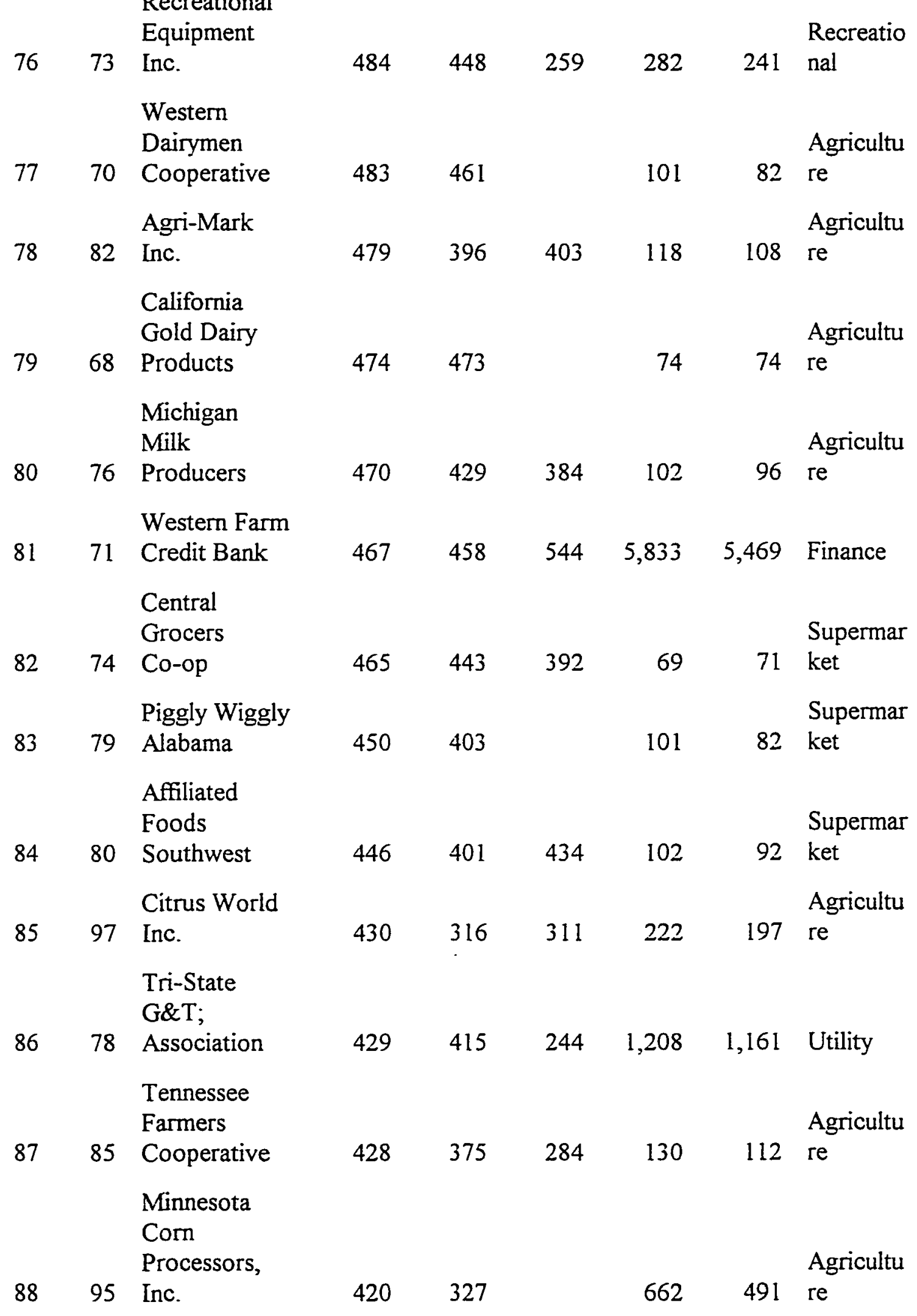




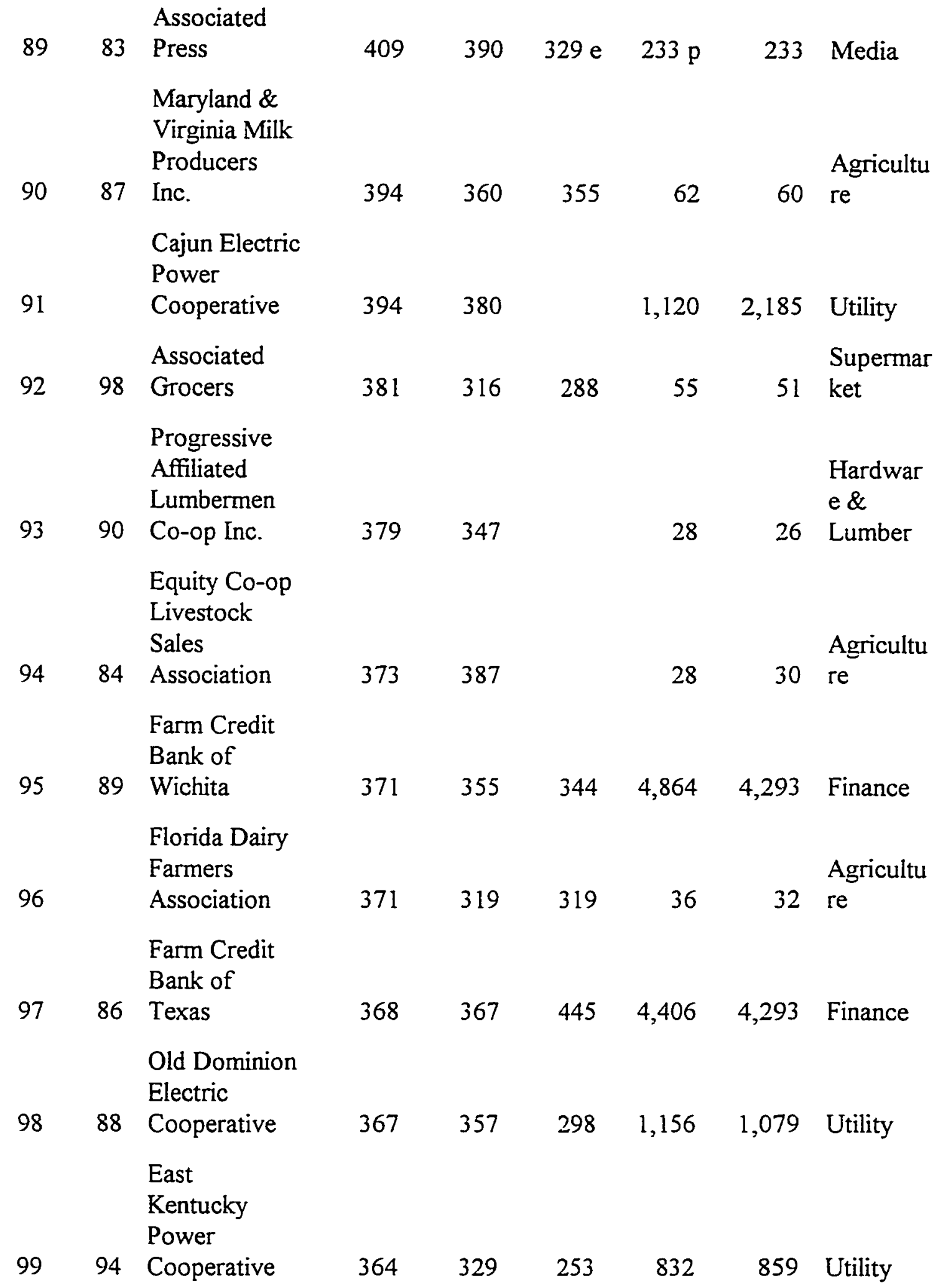




\section{United \\ Dairymen of \\ 100100 Arizona}

360
306
207
Agricultu

41
39 re 


\author{
APPENDIX D \\ FORTUNE 100 \\ (Source: Website of Fortune 500)
}

\begin{tabular}{|c|c|c|c|c|c|}
\hline $\begin{array}{l}\text { FORTUNE } \\
\text { SOORANK }\end{array}$ & COMPANY & 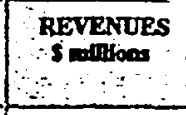 & 17 & Sears, Roebuck \& & 38,236 \\
\hline \multirow[t]{2}{*}{1} & \multirow{2}{*}{$\begin{array}{l}\text { General Motors } \\
\text { Corporation } \\
\end{array}$} & \multirow{2}{*}{168,369} & & & \\
\hline & & & \multirow[t]{2}{*}{18} & \multirow{2}{*}{$\begin{array}{l}\text { The Procier \& Gamble } \\
\text { Company }\end{array}$} & \multirow[t]{2}{*}{35,284} \\
\hline 2 & Ford Motor Company & 146,991 & & & \\
\hline 3 & Exxon Corporation & 119,434 & 19 & Amoco Corporation & 32,726 \\
\hline 4 & Wal-Mart Stores, Inc. & 106,147 & 20 & Citucore & 32,605 \\
\hline \multirow[t]{2}{*}{5} & \multirow{2}{*}{$\begin{array}{l}\text { General Electric } \\
\text { Company }\end{array}$} & \multirow{2}{*}{79,179} & 21 & Pepsico, Inc. & 31,645 \\
\hline & & & 22 & Kman Corporation & 31,437 \\
\hline 6 & $\begin{array}{l}\text { International Business } \\
\text { Machines Corporation }\end{array}$ & 75,947 & 23 & $\begin{array}{l}\text { American International } \\
\text { Group. Inc }\end{array}$ & 28,205 \\
\hline 7 & AT\&T Corp. & 74,525 & 24 & Motorola $\operatorname{lnc}$ & 27,973 \\
\hline 8 & Mobil Corporation & 72,267 & \multirow[t]{2}{*}{25} & \multirow{2}{*}{$\begin{array}{l}\text { The Chase Manhattan } \\
\text { Corporation }\end{array}$} & \multirow[t]{2}{*}{27,421} \\
\hline 9 & Chrysler Comporation & 61,397 & & & \\
\hline 10 & $\begin{array}{l}\text { Phılip Morris } \\
\text { Companies Inc }\end{array}$ & 54,553 & 26 & $\begin{array}{l}\text { Lockheed Martin } \\
\text { Corporation }\end{array}$ & 26,875 \\
\hline 11 & Texaco Inc. & 44,561 & 27 & $\begin{array}{l}\text { Davton Hudson } \\
\text { Corporation } \\
\end{array}$ & 25,371 \\
\hline 12 & $\begin{array}{l}\text { State Farm Insurance } \\
\text { Companies }\end{array}$ & 42,781 & 28 & The Kroger Company & 25,171 \\
\hline \multirow[t]{2}{*}{13} & \multirow{2}{*}{$\begin{array}{l}\text { Prudential Insurance } \\
\text { Company of America } \\
\end{array}$} & \multirow{2}{*}{40,175} & 29 & \multirow{3}{*}{$\begin{array}{l}\text { Fannie Mae } \\
\text { Nerrill Linch \& Co } \\
\text { Inc. }\end{array}$} & 25,054 \\
\hline & & & \multirow[t]{2}{*}{30} & & \multirow[t]{2}{*}{25,011} \\
\hline \multirow[t]{2}{*}{14} & El du Pont de & 39,689 & & & \\
\hline & $\begin{array}{l}\text { Nemours and } \\
\text { Company, Inc. }\end{array}$ & & 31 & ConAgra Inc & 24,822 \\
\hline 15 & Chevron Corporation & 38,691 & $\mid 32$ & $\begin{array}{l}\text { The Allstate } \\
\text { Corporation }\end{array}$ & 24,299 \\
\hline 16 & $\begin{array}{l}\text { Hewlent-Packard } \\
\text { Company }\end{array}$ & 38,420 & 33 & $\begin{array}{l}\text { J.C Pennev Company } \\
\text { Inc. }\end{array}$ & 23,649 \\
\hline
\end{tabular}




\begin{tabular}{|c|c|c|c|c|c|}
\hline & & & $\begin{array}{l}06 \mathrm{R} \\
\mathrm{s}\end{array}$ & W & Propuas \\
\hline \multirow[t]{2}{*}{34} & \multirow{2}{*}{$\begin{array}{l}\text { United Technologies } \\
\text { Corporation }\end{array}$} & \multirow[t]{2}{*}{23,512} & 51 & Xerox Corporation & 19,521 \\
\hline & & & \multirow[t]{2}{*}{52} & \multirow{2}{*}{$\begin{array}{l}\text { Atiantic Richfield } \\
\text { Company }\end{array}$} & \multirow[t]{2}{*}{19,168} \\
\hline \multirow[t]{2}{*}{35} & \multirow{2}{*}{$\begin{array}{l}\text { Metropolitan Life } \\
\text { Insurance Co. }\end{array}$} & \multirow[t]{2}{*}{23,000} & & & \\
\hline & & & \multirow[t]{2}{*}{53} & \multirow{2}{*}{$\begin{array}{l}\text { BellSouth } \\
\text { Corporation } \\
\end{array}$} & \multirow[t]{2}{*}{19,040} \\
\hline 36 & The Boeing Company & 22,681 & & & \\
\hline \multirow[t]{2}{*}{37} & \multirow{2}{*}{$\begin{array}{l}\text { United Parcel Service } \\
\text { of America, Inc. }\end{array}$} & \multirow[t]{2}{*}{22,368} & 54 & CIGNA Corporation & 18,950 \\
\hline & & & \multirow[t]{2}{*}{55} & \multirow{2}{*}{$\begin{array}{l}\text { The Walt Disney } \\
\text { Company }\end{array}$} & \multirow[t]{2}{*}{18,739} \\
\hline \multirow[t]{2}{*}{38} & \multirow{2}{*}{$\begin{array}{l}\text { BankAmerica } \\
\text { Corporation } \\
\end{array}$} & \multirow[t]{2}{*}{22,071} & & & \\
\hline & & & \multirow[t]{2}{*}{56} & \multirow{2}{*}{$\begin{array}{l}\text { American Siores } \\
\text { Company: } \\
\end{array}$} & \multirow[t]{2}{*}{18,678} \\
\hline 39 & Johnson \& Johnson & 21,620 & & & \\
\hline 40 & Travelers Group Inc. & 21,345 & 57 & Sara Lee Corporation & 18,624 \\
\hline 41 & GTE Corporation & 21,339 & \multirow[t]{2}{*}{58} & \multirow{2}{*}{$\begin{array}{l}\text { The Coca-Cola } \\
\text { Compan: }\end{array}$} & \multirow[t]{2}{*}{18,546} \\
\hline 42 & USX Corporation & 21,076 & & & \\
\hline 43 & Intel Corporation & 20,847 & \multirow[t]{2}{*}{59} & \multirow{2}{*}{$\begin{array}{l}\mathrm{MCI} \\
\text { Communications } \\
\text { Corporation }\end{array}$} & \multirow[t]{2}{*}{18,494} \\
\hline \multirow[t]{2}{*}{44} & \multirow{2}{*}{$\begin{array}{l}\text { International Paper } \\
\text { Company } \\
\end{array}$} & \multirow[t]{2}{*}{20,143} & & & \\
\hline & & & \multirow[t]{2}{*}{60} & Compan Compuler & 18,109 \\
\hline 45 & The Dow Chemical & 20,053 & & Corporation & \\
\hline & Company & & 61 & AMR Corporation & 17,753 \\
\hline 46 & Loews Corporation & 19,965 & 62 & NationsBank & 17,509 \\
\hline 47 & Columbia/HCA & 19,909 & & Corporation & \\
\hline & re Corp. & & 63 & New Yorh Life & 17,347 \\
\hline 48 & Merck \& Co. Inc. & 19,829 & & Insurance Compans: & \\
\hline 49 & $\begin{array}{l}\text { Costco Companies. } \\
\text { lnc. }\end{array}$ & 19,566 & 64 & $\begin{array}{l}\text { American Express } \\
\text { Company }\end{array}$ & 17,280 \\
\hline 50 & The Home Depot, Inc. & 19,536 & 65 & Safeway Inc: & 17,269 \\
\hline
\end{tabular}




\begin{tabular}{|c|c|c|c|c|c|}
\hline & \multicolumn{2}{|r|}{ Company } & \\
\hline & & & 82 & Sprint Corporation & 14,235 \\
\hline $\begin{array}{l}\text { FORTUNE } \\
\text { 500RANK }\end{array}$ & COMPANY & $\begin{array}{l}\text { REVENUES } \\
S \text { millions } \\
\text { Sot }\end{array}$ & 83 & $\begin{array}{l}\text { American Home } \\
\text { Products Corporation }\end{array}$ & 14,088 \\
\hline \multirow[t]{2}{*}{66} & \multirow{2}{*}{$\begin{array}{l}\text { RJR Nabisio } \\
\text { Holdings Corporation }\end{array}$} & \multirow[t]{2}{*}{17,063} & 84 & AlliedSignal inc. & 13,971 \\
\hline & & & \multirow{2}{*}{85} & \multirow{2}{*}{$\begin{array}{l}\text { SBC } \\
\text { Communications Inc }\end{array}$} & \multirow{2}{*}{13,898} \\
\hline 67 & Aetna, Inc. & 16,900 & & & \\
\hline 68 & Caterpillar, Inc & 16,522 & \multirow[t]{2}{*}{86} & \multirow{2}{*}{$\begin{array}{l}\text { College Retirement } \\
\text { Equities Fund }\end{array}$} & \multirow[t]{2}{*}{13,865} \\
\hline \multirow{2}{*}{69} & \multirow{2}{*}{$\begin{array}{l}\text { Fleming Companies, } \\
\text { Inc. }\end{array}$} & \multirow{2}{*}{16,487} & & & \\
\hline & & & \multirow[t]{2}{*}{87} & \multirow{2}{*}{$\begin{array}{l}\text { McDonnell Douglas } \\
\text { Corporation }\end{array}$} & \multirow[t]{2}{*}{13,834} \\
\hline 70 & Supervalu. $\ln c$ & 16,486 & & & \\
\hline 71 & UAL Corporation & 16,362 & \multirow[t]{2}{*}{88} & \multirow{2}{*}{$\begin{array}{l}\text { Teachers Insurance \& } \\
\text { Annuity dssociation } \\
\text { of America }\end{array}$} & \multirow[t]{2}{*}{13,828} \\
\hline \multirow[t]{2}{*}{72} & \multirow{2}{*}{$\begin{array}{l}\text { Eastman Kodak } \\
\text { Company }\end{array}$} & \multirow[t]{2}{*}{15,968} & & & \\
\hline & & & 89 & Albertson's, Inc. & 13,777 \\
\hline 73 & $\begin{array}{l}\text { J.P. Morgan \& Co } \\
\text { Incorporited }\end{array}$ & 15,866 & 90 & $\begin{array}{l}\text { Mckesson } \\
\text { Corporation }\end{array}$ & 13,719 \\
\hline 74 & $\begin{array}{l}\text { Phillips Petroleum } \\
\text { Compant }\end{array}$ & 15,807 & 91 & NYNEX Corporation & 13,454 \\
\hline \multirow{2}{*}{75} & \multirow{2}{*}{$\begin{array}{l}\text { Federated } \\
\text { Departme nt } s \sigma e s \\
\text { Inc. }\end{array}$} & \multirow{2}{*}{15,229} & 92 & SYSCO Corporation & 13,395 \\
\hline & & & 93 & $\begin{array}{l}\text { Archer Daniels } \\
\text { Midland Company }\end{array}$ & 13,314 \\
\hline \multirow[t]{2}{*}{76} & \multirow{2}{*}{$\begin{array}{l}\text { Bristol-Mvers Squibb } \\
\text { Companv }\end{array}$} & \multirow[t]{2}{*}{15,065} & 94 & Enron Corp. & 13,289 \\
\hline & & & \multirow[t]{2}{*}{95} & \multirow{2}{*}{$\begin{array}{l}\text { Kimberly-Clark } \\
\text { Corporation }\end{array}$} & \multirow[t]{2}{*}{13,149} \\
\hline \multirow[t]{2}{*}{77} & Ameritech & 14,917 & & & \\
\hline & Corporation & & 96 & Morgan Stanley & 13,144 \\
\hline 78 & Digital Equipment & 14,563 & & Group & \\
\hline & Corporation & & 97 & Alcoa & 13,128 \\
\hline 79 & $\begin{array}{l}\text { Rockwell } \\
\text { International } \\
\text { Corporation }\end{array}$ & 14,343 & 98 & $\begin{array}{l}\text { The Goodvear Tire \& } \\
\text { Rubber Company }\end{array}$ & 13,113 \\
\hline 80 & $\begin{array}{l}\text { Lehman Brothers } \\
\text { Holdings Inc }\end{array}$ & 14,260 & 99 & $\begin{array}{l}\text { Bell Atlantic } \\
\text { Corporation } \\
\end{array}$ & 13,081 \\
\hline 81 & $\begin{array}{l}\text { Mlinnesota Wining \& } \\
\text { Manufacturing }\end{array}$ & 14,236 & 100 & $\begin{array}{l}\text { Georgia-Pacific } \\
\text { Corporation }\end{array}$ & 13,024 \\
\hline
\end{tabular}




\section{APPENDIX E \\ PART I, CHAPTER 5 OF TEE PENSAMIENTOS}

\section{Education}

\subsection{Culture and Personality}

170 The human being is human more through education than through birth.

171 As much and only through education can human beings arrive at being human.

172 "Man is not so much born as he is made through education."

173 Beyond being born human, we are made human by virtue of an educational process in its broader meaning; by virtue of certain knowledge, of a certain experience.

174 Man makes himself human through education. Civilization progresses at an increasing pace always through formative and educative action along the path of searching for human and social values.

175 Human nature is not like dried goods but rather like artifacts, that is, nature transformed, adapted or developed by work and technology.

176 In a wild forest, the energy and vigor of the earth is equally spent on sap that renders a fruit tree fecund and bear delicious fruits as well as on sap that renders thorns and brambles to Elourish.

177 Education is the economy; since without education scarce goods and services cannot be produced nor distributed.

178 It is easier to educate a young person than to reform an adult.

179 Teaching should be ongoing in order to be efficient.

18 Tools and machines need be updated but above all there has a to be a change in mentality among those who are slated 
to run these tools and machineries

181 Culture is the blood that always gives lineage and nobility to people

182 The only patrimony and value that does not tend to devalue itself is that of skills acquisition, that of training and formation.

183 Intelligence is the unshakeable foundation of equality that God has planted in all men.

\subsection{Culture and Emancipation}

184 knowledge is power.

185 Knowledge must be socialized if power is to be democratized.

186 After the socialization of education inevitably comes the socialization of wealth and power; we may say that this is the indispensable and prior condition for the democratization and socio-economic progress of a people.

187 Let us not forget that the bourgeoisie overcame and dethroned the aristocracy when they attained a superior education. Iikewise the proletariat will be in a position to begin its social dominance when it is able to replace or relieve the bourgeoisie through its technical and cultural preparation and ability.

188 The transformation and cultivation of man through education is an inescapable presupposition in all occasions and in all the suppositions of social structures.

189 The most active agents of renewal are culture, science, and technology and these have a common denominator in a man with a new mentality.

190 Education understood as the complex of ideas and thoughts that one adopts, is the key to the development and evolution of a people.

191 Education is the natural and indispensable point of support for the promotion of a new social order, humane and just.

192 We should be concerned about the underdeveloped areas which are found almost anywhere, but especially those that 
are under our hats and berets...

The imperative of the present hour under all aspects of life and human relations is the opening and the projection of our minds. It imposes a radical change of mentality.

193 knowledge is power and in order to democratize power, one must socialize knowledge beforehand. We accomplish nothing with the proclamation of rights, if afterwards the citizens whose rights we have proclaimed are incapable of administering those rights, if to be able to act, these citizens have no recourse but to count on a few indispensable people.

194 The emancipation of a class or of a people must begin with the empowerment, more or less massive, of all sectors of society. One does not improve the lot of the masses without the masses.

195 Many times we say that we ought to fight against social injustice, against the exploitation of the wage earner, against excessive accumulation of wealth, etc., etc., but have we understood that the principal servitude, the first and most serious enslavement is the poverty of the intellect.?

196 We should regard the lack of opportunities for education and training as the worse inheritance from the generation before us rather than the inequalities in economic standing.

197 The young man who enters the world of work without a clear and positive (social) vision is a shipwreck in his spiritual life or a coward and traitor to the workers' movement.

198 We believe that more than lack of imagination we suffer the burden of vested interests and the inertia of an unreliable culture. The former renders the powerful and influential sclerotic and the latter keeps the masses lethargic. These are the real causes of our troubles and lack of potential.

199 "Culture" as the privilege of one class is one of the major drawbacks of a community with regard to its progress; sometimes it implies an anti-social and anti-economicdevelopment (sentiment). Those who recognize this fact without difficulty try to socialize culture at all costs. The socialization of culture, the access to it by the community without discrimination, the granting of opportunities for improvement to all to the extent of every 
person's potential, is a fundamental postulate of all social movement in our times. The proclamation of human rights that are made without a corresponding economic and cultural guarantee are ephemeral concessions for show and are not destined to produce the best results.

200 We know the longing for liberty of the humble, of the proletariat, in a word, of the people. These longings are very good and speak very well in favor of the people,. 201 Education is an indispensable element in the authentic emancipation of the worker.

202 People who are conscious of their dignity, or who would not want to be at some foreign and outside mercy must promote before everything the cultivation and development of its own intelligence and will.

203 The enhancement of the talents of our people regardless of their economic condition--be it personal, be it that of the family--is the fundamental premise of all social action that is directed toward realizing a social order that is more human and more Christian.

204 The socialization of culture [through education] has priority over the redistribution of wealth because the former enables us to think on the authentic humanization of work.

205 The ignorant person is more dangerous than the wicked person because the wicked person rests every now and then [from his wicked ways] and the ignorant never.

206 Our heads are the underdeveloped regions that we must attend to even more.

207 The most productive and profitable prediction is that which we can apply toward making men upon whom (sane) humane villages can be raised and set.

208 The best way that a community can become dynamic, blossoming in all kinds of initiatives, is the granting of many option to all who are in the position to cultivate their higher faculties.

209 Education is the key to the good fortune and future of our youth and of our very own society.

210 Under no circumstances can we dream of a better tomorrow if we don't busy ourselves preparing it, precisely forming 
the tender souls of those who next will be the men and women of tomorrow.

211 Children are our glory, or our ruin, and whether they become one or the other depends on what our educational program would give them.

212 Our good fortune of tomorrow depends more on the classrooms that we have gone through than the cribs in which we were born.

213 Plants take time to grow deep roots into the earth. We can say the same thing of sentiments and ideas taking time to grow into the spirits of men and people with one difference in that the latter takes more time than the former. For, while the life of plants is measured in five years or in centuries, the story of people ordinarily is counted in thousands of years.

214 The formation of persons begins a hundred years before their birth.

215 To change the constitution of a nation, to change the form or rule of a government, is something that can be done overnight. Likewise, to change the laws. To put something else ahead of others is relatively easy. It doesn't need much time. But no one will doubt that to change the beast in man, to perfect oneself a little, to control and overcome the bad inclinations that are born in all of us, is something that takes time and effort. It does not lend to improvisation.

\section{Teaching and learning are the first enterprise of a people.}

\subsection{Education and Cooperativism}

217 Education and cooperation are linked in the same way that work and the worker are, developing individually and collectively, overcoming the native and characteristic inertia in disposition and self-importance.

218 It has been said that cooperativism is an economic movement that uses the methods of education. The definition may also be modified to emphasize that Cooperativism is an educational movement which uses the methods of economics.

219 As a didactic and existential process, education has to introduce extraneously a dose of conscience and the habit of 
work.

220 Work and study ought to go hand in hand. One must never cease to pay attention to the potential of those who work nor underestimate the options to work whenever study gets bogged down or when one gets tired.

The equality of opportunities ought to continue to have a bearing throughout life if, indeed, we want our communities to be adaptable.

221 Democracy does not mix well with inherited privileges.

222 The excellence of the principle of opportunities in education ought to be compatible with the requirements of equitable distribution of the responsibilities that are indispensable to its realization.

223 Let's marry WORK to CUITURE, let's keep them tied together in the service of a progressive community, for the good of people.

224 Cooperative enterprises must flee from irremovableness and return regularly to the training of its people, carefully considering their aptitudes, and to actualize them or adjust them systematically.

225 In order to put the human potential under the best circumstances, one must apply the means of promotion as carefully as one carries out financial plans.

226 Formation is much like the cultivation of all human virtues, among which stands out especially the capacity to think.

227 Ideas and the mentality they promote are as indispensable for the progress of our cooperatives as the installations and machineries. 


\section{REFERENCES}

Azurmendi, Joxe. El Hombre Cooperativo. Mondragon, Spain: Caja Laboral popular, 1984. Translations mine.

Pensamientos de Don Jose Maria Arizmendiarrieta. Mondragon, Spain: Caja Laboral Popular, 1983. Translations mine and by David Herrera.

Freire, Paolo. Pedagogy of the Oppressed. Translated by Myra B. Ramos. New York, NY: Continuum, 1997.

Greenwood, Davydd, Jose Luis Gonzales, et al. Culturas de Fagor: Estudio Antropologico de las Cooperativas de Mondragon. San Sebastian, Spain: Editorial Txertoa, 1989. Translations mine.

Hahn, Lewis E., ed. The Philosophy of Paul Ricoeur. Vol. 22, The Library of Living Philosophers. Chicago, IL: Open Court, 1995.

Maguire, Daniel C. and A. Nicholas Fargnoli. On Moral Grounds. New York, NY: The Crossroad Publishing Company, 1996.

Mondragon Cooperative Corporation. Annual Report. Mondragon, Spain: MCC, 1996.

- Trabajo Y Union. Mondragon, Spain: MCC, November, 1986 and November, 1996. Translations mine.

National Catholic Conference of Bishops. Economic Justice For All. Washington, D.C.: NCCB/USCC, 1986.

Ricoeur, Paul. From Text to Action. Translated by Kathleen Blamey and John B. Thompson. Evanston, IL: Northwestern University Press, 1991.

- Oneself As Another. Translated by Kathleen Blamey Chicago: University of Chicago Press, 1992.

Whyte, William F. and Kathleen $\mathrm{K}$. Whyte. Making Mondragon. Ithaca, NY: ILR Press, 1991. 